\title{
Medial Frontal Theta Is Entrained to Rewarded Actions
}

\author{
Linda M. Amarante, ${ }^{1}{ }^{-}$Marcelo S. Caetano, ${ }^{2}$ and Mark Laubach ${ }^{1}$ \\ ${ }^{1}$ Department of Biology and Center for Behavioral Neuroscience, American University, Washington, DC 20016, and ${ }^{2}$ Center for Mathematics, Computation \\ and Cognition, Universidade Federal do ABC (UFABC), Rua Santa Adélia, 166. Santo André-SP-09210-170, Brazil
}

Rodents lick to consume fluids. The reward value of ingested fluids is likely to be encoded by neuronal activity entrained to the lick cycle. Here, we investigated relationships between licking and reward signaling by the medial frontal cortex (MFC), a key cortical region for reward-guided learning and decision-making. Multielectrode recordings of spike activity and field potentials were made in male rats as they performed an incentive contrast licking task. Rats received access to higher-and lower-value sucrose rewards over alternating $30 \mathrm{~s}$ periods. They learned to lick persistently when higher-value rewards were available and to suppress licking when lower-value rewards were available. Spectral analysis of spikes and fields revealed evidence for reward value being encoded by the strength of phase-locking of a $6-12 \mathrm{~Hz}$ theta rhythm to the rats' lick cycle. Recordings during the initial acquisition of the task found that the strength of phase-locking to the lick cycle was strengthened with experience. A modification of the task, with a temporal gap of $2 \mathrm{~s}$ added between reward deliveries, found that the rhythmic signals persisted during periods of dry licking, a finding that suggests the MFC encodes either the value of the currently available reward or the vigor with which rats act to consume it. Finally, we found that reversible inactivations of the MFC in the opposite hemisphere eliminated the encoding of reward information. Together, our findings establish that a 6-12 Hz theta rhythm, generated by the rodent MFC, is synchronized to rewarded actions.

Key words: licking; muscimol; prefrontal; reward; sucrose; theta

\section{Significance Statement}

The cellular and behavioral mechanisms of reward signaling by the medial frontal cortex (MFC) have not been resolved. We report evidence for a 6-12 Hz theta rhythm that is generated by the MFC and synchronized with ongoing consummatory actions. Previous studies of MFC reward signaling have inferred value coding upon temporally sustained activity during the period of reward consumption. Our findings suggest that MFC activity is temporally sustained due to the consumption of the rewarding fluids, and not necessarily the abstract properties of the rewarding fluid. Two other major findings were that the MFC reward signals persist beyond the period of fluid delivery and are generated by neurons within the MFC.

\section{Introduction}

Reward-related neuronal activity is commonly found in the medial frontal cortex (MFC), also known as mPFC, of humans (Gläscher et al., 2009; Levy and Glimcher, 2011), primates (Watanabe, 1996; Shidara and Richmond, 2002; Roesch and Olson, 2004; Amiez et al., 2006; Padoa-Schioppa and Assad, 2006; Hayden et al., 2009; Luk and Wallis, 2009; Bouret and Richmond,

Received July 11, 2017; revised Sept. 21, 2017; accepted Sept. 25, 2017.

Author contributions: L.M.A., M.S.C., and M.L. designed research; L.M.A. and M.S.C. performed research; L.M.A. and M.L. analyzed data; L.M.A. and M.L. wrote the paper.

This work was supported by National Science Foundation Grant 1121147, National Institutes of Health Grant DK099792-01A1, Klarman Family Foundation (two grants) to M.L., and a National Science Foundation Graduate Research Fellowship to L.M.A. We thank Alexxai Kravitz, Catherine Stoodley, and Kyra Swanson for helpful comments on the manuscript.

The authors declare no competing financial interests.

Correspondence should be addressed to Dr. Mark Laubach, Department of Biology, Center for Behavioral Neuroscience, American University, 4400 Massachusetts Avenue NW, Washington, DC 20016-8062. E-mail: mark.laubach@american.edu.

DOI:10.1523/JNEUROSCI.1965-17.2017

Copyright $\odot 2017$ the authors $\quad 0270-6474 / 17 / 3710757-13 \$ 15.00 / 0$
2010; Cai and Padoa-Schioppa, 2012), and rodents (Petyko et al., 2009; Horst and Laubach, 2012, 2013; Donnelly et al., 2014; Petyko et al., 2015). However, the behavioral determinants of these signals are not understood. In neurophysiological studies in experimental animals, rewards are typically given as liquids (Apicella et al., 1991; Carelli and Deadwyler, 1994) to avoid issues with chewing and grinding foods. A fixed cycle of specific behaviors (jaw opening, tongue protrusion and retraction, jaw closing, swallowing) underlies the processing of liquid rewards. These behaviors should have a major impact on reward signaling by the MFC.

Indeed, Horst and Laubach (2012) reported that MFC activity is sharply modulated when thirsty rats lick to consume water rewards in an MFC-dependent working memory task (Horst and Laubach, 2009). By modifying the task to delay the delivery of water on some trials, a subpopulation of MFC neurons was revealed that were selectively activated by the initiation of licking (Horst and Laubach, 2013). These changes in spike activity are accompanied by prominent fluctuations of MFC local field poten- 
tials (LFPs), specifically near the rats' licking frequency $(5-7 \mathrm{~Hz})$. These signals were most prevalent in the most rostral MFC. A subsequent study found that reversible inactivation of this rostral part of the MFC dramatically reduces the duration of licking bouts (Parent et al., 2015a), similar to how inactivation of the more caudal MFC leads to excessive premature responding in tasks that require actions to be sustained over delay periods (e.g., Narayanan et al., 2006). These studies suggest that the rostral MFC is specialized for the value-guided control of consummatory behavior.

The goal of the present study was to determine whether licking-related neuronal activity in the rostral MFC is sensitive to the reward value of ingested fluids. To examine this issue, we used a simple take-it-or-leave decision-making task, called the shifting values licking task (Parent et al., 2015a, b), to study reward signaling in relation to ongoing consummatory actions. Rats lick on a spout to receive liquid sucrose rewards and the concentration of sucrose alternates between a higher (better) and lower (worse) option every $30 \mathrm{~s}$. After only a few days of training, the rats learn to persistently lick when the better option is available and to suppress licking when the worse option is available. Bilateral reversible inactivations of the rostral MFC impair performance in this task (Parent et al., 2015a), resulting in temporally fragmented licking (dramatic reductions in the duration of licking bouts). Opposite effects are found after intra-MFC infusions of drugs that are known to enhance neuronal excitability near the licking frequency, such as the M-channel blocker XE-991 (Hu et al., 2002), and the "hunger hormone" ghrelin (Parent et al., 2015b).

To examine how the rostral MFC encodes reward information and controls value-guided consumption, we recorded spike activity and LFPs as rats performed the shifting values licking task. We found that neuronal activity in the MFC is entrained to the lick cycle when animals consume liquid sucrose rewards. These signals develop with experience, persist beyond periods of fluid delivery, and depend on MFC neurons. Together, our findings suggest that a $6-12 \mathrm{~Hz}$ rhythm generated by MFC neurons tracks engagement in reward-based consummatory behavior and encodes reward information.

\section{Materials and Methods}

Procedures were approved by the Animal Use and Care Committees at the John B. Pierce Laboratory (where some of the experiments were conducted) and American University and conformed to the standards of the National Institutes of Health Guide for the care and use of laboratory animals. All efforts were taken to minimize the number of animals used and to reduce pain and suffering.

Experimental design: animals. Male Long-Evans rats weighing between 300 and $325 \mathrm{~g}$ were purchased from Harlan or Charles River. Rats were given 1 week to acclimate with daily handling before behavioral training or surgery and were then kept with regulated access to food to maintain $90 \%$ of their free-feeding body weight. They were given $\sim 18 \mathrm{~g}$ of standard rat chow each day in the evenings following experiments. Rats were single-housed in their home cages in a $12 \mathrm{~h}$ light/dark cycle colony room, with experiments occurring during the light cycle. A total of 11 rats had a microwire array implanted into MFC. Some rats additionally had a drug cannula implanted into the opposite hemisphere using the same stereotaxic coordinates. Arrays were made by Tucker-Davis Technologies and consisted of 16 blunt-cut $50 \mu \mathrm{m}$ tungsten wires, insulated with Formvar, separated by $250 \mu \mathrm{m}$ within each row and $500 \mu \mathrm{m}$ between rows. In vitro impedances for the microwires were $\sim 150 \mathrm{k} \Omega$.

Surgeries. Animals had full access to food and water in the days before surgery. Stereotaxic surgery was performed using standard methods (e.g., Narayanan and Laubach, 2006). Briefly, animals were lightly anesthetized with isoflurane $(2.5 \%$ for $\sim 2 \mathrm{~min})$ and were then injected intraperitoneally with ketamine $(100 \mathrm{mg} / \mathrm{kg})$ and either xylazine $(10 \mathrm{mg} / \mathrm{kg})$ or dexdomitor $(0.25 \mathrm{mg} / \mathrm{kg})$ to maintain a surgical plane of anesthesia.
Craniotomies were made above the implant location. Microwire arrays were placed into the MFC (coordinates from bregma: anteroposterior $3.2 \mathrm{~mm}$; mediolateral $\pm 1.0 \mathrm{~mm}$; dorsoventral $-2.2 \mathrm{~mm}$ from the surface of the brain, at a $12^{\circ}$ posterior angle). Four skull screws were placed along the edges of the skull, and a ground wire was secured in the intracranial space above the posterior cerebral cortex. Electrode arrays were connected to a headstage cable and modified Plexon preamplifier during surgery, and recordings were made to assess neural activity during array placement. Drug cannulas (26-gauge PEEK, Plastics One) were implanted before the microwire arrays using similar procedures. Craniotomies were sealed using cyanocrylate (Slo-Zap) and an accelerator (Zip Kicker), and methyl methacrylate dental cement (AM Systems) was applied and affixed to the skull via the skull screws. Animals were given a reversal agent for either xylazine (yohimbine, $2 \mathrm{mg} / \mathrm{ml}$ ) or dexdomitor (Antisedan, $0.25 \mathrm{mg} / \mathrm{ml}$, s.c.), and carprofen $(5 \mathrm{mg} / \mathrm{kg}$, s.c.) was administered for postoperative analgesia. Animals recovered from surgery in their home cages for at least 1 week with full food and water, and were weighed and handled daily.

Behavioral apparatus. Rats were trained in operant chambers housed within a sound-attenuating external chamber (Med Associates). Operant chambers contained a custom-made drinking spout that was connected to multiple fluid lines allowing for multiple fluids to be consumed at the same location. The spout was centered on one side of the operant chamber wall at a height of 5-6.5 cm from the chamber floor. Tygon tubing connected to the back of the drinking spout would administer the fluid from a 60 cc syringe hooked up to a PHM-100 pump (Med Associates). A "light-pipe" lickometer (Med Associates) detected licks via an LED photobeam, and each lick triggered the pump to deliver $\sim 0.025 \mathrm{ml} / 0.5 \mathrm{~s}$. Behavioral protocols were run though Med-PC version IV (Med Associates), and behavioral data were sent via TTL pulses from the Med-PC software to the Plexon recording system.

Continuous-access shifting values licking task. The operant licking task used here is similar to that previously described by Parent et al. (2015a, b). Briefly, rats were placed in the operant chamber for $30 \mathrm{~min}$, where they were solely required to lick at the drinking spout to obtain a liquid sucrose reward. Licks activated the syringe pumps to deliver liquid sucrose over $0.5 \mathrm{~s}$. Every $30 \mathrm{~s}$, the reward alternated between a high concentration (20\% weight per volume) and low concentration $(2 \%-4 \% \mathrm{w} / \mathrm{v})$ of sucrose. The animal's licking behavior was constantly monitored.

Instrumental shifting values licking task. The operant licking task used above was modified slightly to allow for assessment of reinforced versus nonreinforced licks. A 2 s interpump interval was included between each pump activation. In other words, the rat would lick to activate a liquid sucrose reward for $0.5 \mathrm{~s}$, and then once the pump stopped delivering fluid, no reward was delivered again for $2 \mathrm{~s}$. The next lick after the $2 \mathrm{~s}$ interval would initiate the next pump activation. Licks during the $2 \mathrm{~s}$ interpump interval were instrumental.

Multielectrode recordings. Electrophysiological recordings were made using a Multichannel Acquisition Processor (Plexon). LFPs were sampled on all electrodes and recorded continuously throughout the behavioral testing sessions using the Plexon system via National Instruments A/D card (PCI-DIO-32HS). The sampling rate was $1 \mathrm{kHz}$. The headstage filters (Plexon) were at $0.5 \mathrm{~Hz}$ and $5.9 \mathrm{kHz}$. Electrodes with unstable signals or prominent peaks at $60 \mathrm{~Hz}$ in plots of power spectral density were excluded from quantitative analysis.

Reversible inactivation. Animals were tested with muscimol infusions in one hemisphere and recordings of neural activity in the opposite hemisphere. For control sessions, PBS was infused into MFC. The next day, muscimol (Sigma-Aldrich) was infused at $0.1 \mu \mathrm{g} / \mu \mathrm{l}$. Infusions were performed by inserting a 33-gauge injector into the guide cannula, and $1.0 \mu \mathrm{l}$ of fluid was delivered at a rate of $15 \mu \mathrm{l} / \mathrm{h}(0.25 \mu \mathrm{l} / \mathrm{min})$ with a syringe infusion pump (KDS Scientific). The injector was connected to a $10 \mu \mathrm{l}$ Hamilton syringe via $0.38 \mathrm{~mm}$ diameter polyethylene tubing. After infusion was finished, the injector was left in place for at least 4 min to allow for diffusion of the fluid. The injector was slowly removed, and the headstage cable was subsequently plugged into the animal's implant. Rats were tested in the instrumental shifting values licking task $1 \mathrm{~h}$ after the PBS or muscimol infusions. Recordings were made the day following the infusion session without any manipulation to verify recovery from the inactivation session. 
A

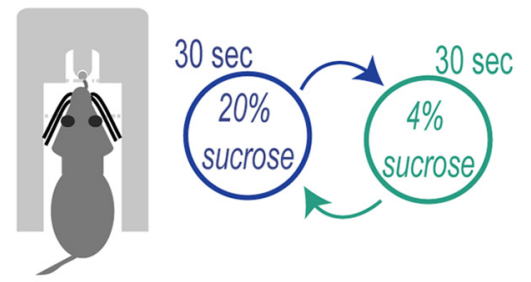

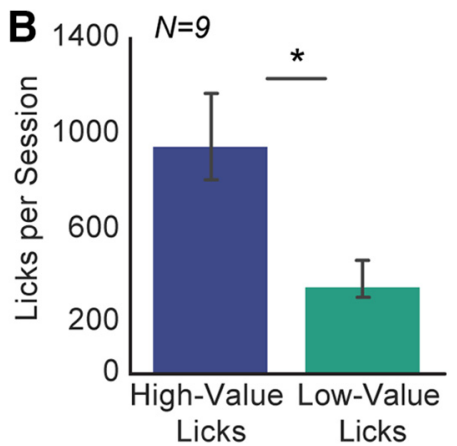

Figure 1. Behavioral task. A, Rats were tested in an incentive contrast procedure called the shifting values licking task (Parent et al., 2015a). They were required to lick on a spout to receive liquid sucrose rewards. Reward values shift between relatively high $(20 \% \mathrm{w} / \mathrm{v}$ ) and low ( $4 \%$ or $2 \% \mathrm{w} / \mathrm{v}$ ) concentrations of sucrose every $30 \mathrm{~s}$. B, Experienced rats (fourth training session) licked more for the high-value sucrose than for the low-value sucrose (paired $t$ test; $\left.t_{(8)}=4.29, p=0.0026\right) .{ }^{*} p<0.005$.

Histology. After all experiments were completed, rats were deeply anesthetized via an intraperitoneal injection of Euthasol $(100 \mathrm{mg} / \mathrm{kg})$ and then transcardially perfused using $4 \%$ PFA in PBS. Brains were cryoprotected with a $20 \%$ sucrose and $10 \%$ glycerol mixture and then sectioned horizontally on a freezing microtome. The slices were mounted on gelatin-subbed slides and stained for Nissl substance with thionin.

Statistical analysis: software and testing. All data were analyzed using GNU Octave (https://www.gnu.org/software/octave/), Python (Anaconda distribution: https://www.continuum.io/), and R (https://www. r-project.org/). Analyses were run as Jupyter notebooks (http://jupyter. org/). Statistical testing was performed using standard (base) packages for R. Standard nonparametric tests and paired $t$ tests were used throughout the study. Repeated-measures ANOVA (with the error term due to subject) were used to compare data across training sessions (see Fig. 7), reinforced versus nonreinforced licks (see Fig. 9), and PBS versus muscimol (see Fig. 10). Computer code used in this study is available upon request from the corresponding author.

Data analysis: behavioral measures of licking. The average licking frequency for each rat was calculated by obtaining the inverse of the median interlick interval (ILI) across the behavioral session. Variability in this measure was estimated using the interquartile range.

To normalize the number of licks emitted in different reinforced or nonreinforced contexts that had different time lengths, licks per unit time (see Fig. $9 B$ ) were calculated by dividing the number of licks in each context by the actual amount of time spent in each context across the session. This was done by finding the sum of times between each context, and then subtracting from that time the amount of time of fluid delivery over the entire session.

Duration of licking bouts was detected as in Parent et al. (2015a, b). Bouts of licks were defined as having at least 3 licks within $300 \mathrm{~ms}$ and with an interbout interval of $\geq 0.5 \mathrm{~s}$.

Data analysis: LFPs. Electrophysiological data were first briefly assessed in NeuroExplorer (http://www.neuroexplorer.com/). Subsequent processing was done using signal processing routines in GNU Octave. Analysis of LFP data was performed using the EEGlab toolbox (https://sccn.ucsd. edu/wiki/EEGLAB_Wiki) (event-related spectral power [ERSP] and intertrial coherence [ITC]) and Neurospec 2.0 (http://www.neurospec. $\mathrm{org} /$ ) (spike-lick and spike-field coherence). Circular statistics were calculated using the circular library for R (Agostinelli and Lund, 2013). Graphical plots of data were made using the matplotlib and seaborn library for Python. Analyses were typically conducted in Jupyter notebooks, and interactions between Python, R, and Octave were implemented using the $r p y 2$ and oct2py libraries for Python.

To measure the amplitude and phase of LFP in the frequency range of licking, LFPs were bandpass-filtered using EEGlab's eegfilt function, with an firl filter (Widmann and Schröger, 2012), centered at the rat's licking frequency (licking frequency \pm interquartile range, typically $\sim 4-9 \mathrm{~Hz}$ ), and were subsequently $z$-scored. Analyses were performed with a prewindow/postwindow of $2 \mathrm{~s}$, to capture effects at low frequencies, and the Hilbert transform was used to obtain the amplitude and phase of the LFP.
To measure the consistency of LFP phase angles in relation to licking, 500 licks were randomly chosen from one session from each rat along with 500 random time points that were chosen based on shuffling the ILIs from all licks in the rat's session. After creating perievent matrices from filtered and $z$-scored LFP data, the Hilbert transform was applied to obtain the phase angle and amplitude for each electrode, and analyzed with routines from the circular library for R. rho.circular was used to obtain mean resultant vector length. mean.circular was used to obtain average phase. The rao.spacing.test function was used to obtain Rao's statistic and corresponding $p$ value, which indicates whether phase angles were uniformly distributed.

For time-frequency analysis (ERSP and ITC), LFPs were preprocessed using EEGlab's eegfilt function with an fir 1 filter and bandpass filtered from 0 to $100 \mathrm{~Hz}$. For group summaries, ERSP and ITC matrices were $z$-scored for that given rat after bandpass filtering the data. Perilick matrices were then formed by using a prewindow/postwindow of $2 \mathrm{~s}$ on each side, and the newtimef function from the EEGlab toolbox was used to generate the time-frequency matrices up to $30 \mathrm{~Hz}$. Plots of ERSP and ITC matrices were made using a narrow time window $(\sim 0.5 \mathrm{~s})$ to focus on effects over several ILIs. Group summaries for ERSP and ITC were performed by obtaining the peak ITC value within a time window of \pm 2 ILIs (typically $\sim \pm 375 \mathrm{~ms}$ ) around licking, and obtaining the peak ERSP value within that same window. Each electrode's peak ERSP and ITC value for each type of lick (highvalue or low-value lick) was used in the ANOVAs for group summaries. Finally, a "value index" was calculated to assess differences in ERSP and ITC measures associated with consumption of the higher- and lowervalue rewards [i.e. $\left(\mathrm{ITC}_{\mathrm{Hi}}-\mathrm{ITC}_{\mathrm{Lo}}\right) / \mathrm{ITC}_{\mathrm{Hi}}$ ].

Shuffling methods were used to compare ERSP and ITC values for observed and shuffled licks (obtained by calculating ILIs, shuffling their trial order, and adding the intervals to the first lick in each behavioral session). This gave a set of surrogate licks with random timing unrelated to the animal's behavior. Subsets of 50 licks and shuffled events were randomly chosen from each behavioral session, and ERSP and ITC statistics were calculated for the subsets of observed and shuffled data. Shuffling was used to assess synchronous (theta) and asynchronous (delta) frequency ranges in the ERSP and ITC analyses (see Fig. 5). However, statistical comparisons of ERSP and ITC values were made using raw spectral values.

Given the imbalance in the number of higher- and lower-value licks across the periods of learning and in the later testing sessions, all results were verified with subsampled sets of licks that were matched to the less represented condition (the square root of the less represented type) as well as using just 50 licks per type. Effects were consistent across these measures. Effects were also validated using the first 5 and $10 \mathrm{~min}$ of each testing condition, which were equivalent to effects across the entire session. To further assess the stability of the ERSP and ITC measures over the test sessions, the datasets were broken into 10 blocks with equal numbers of licks or equal amounts of time into the session. Peak ERSP and ITC values were calculated for frequencies between 4 and $12 \mathrm{~Hz}$ and within 2 ILIs around each lick. Summaries for each rat used grand average LFPs ( $z$-scored). Plots of peak ERSP and ITC over the two types of blocks (licks, time) revealed no consistent cross-session effects (e.g., due to satiety) (de Araujo et al., 2006; Bouret and Richmond, 2010), for both measures of neuronal activity (see Fig. 6).

Data analysis: spike activity. Exploratory analysis of online identified single units found that spike probabilities at the times of the licks were $<0.1$ for all single units recorded in the task. Therefore, we used multiunit activity (MUA) to relate spike activity to the animals' lick cycles and related LFP signals. MUA was identified using the Offline Sorter version 4.3 (Plexon). All recorded spike waveforms were thresholded $( \pm 2.7$ times the SD for the collection of waveforms) and "automatic artifact invalidation" was applied. Then, using routines in NeuroExplorer ver- 

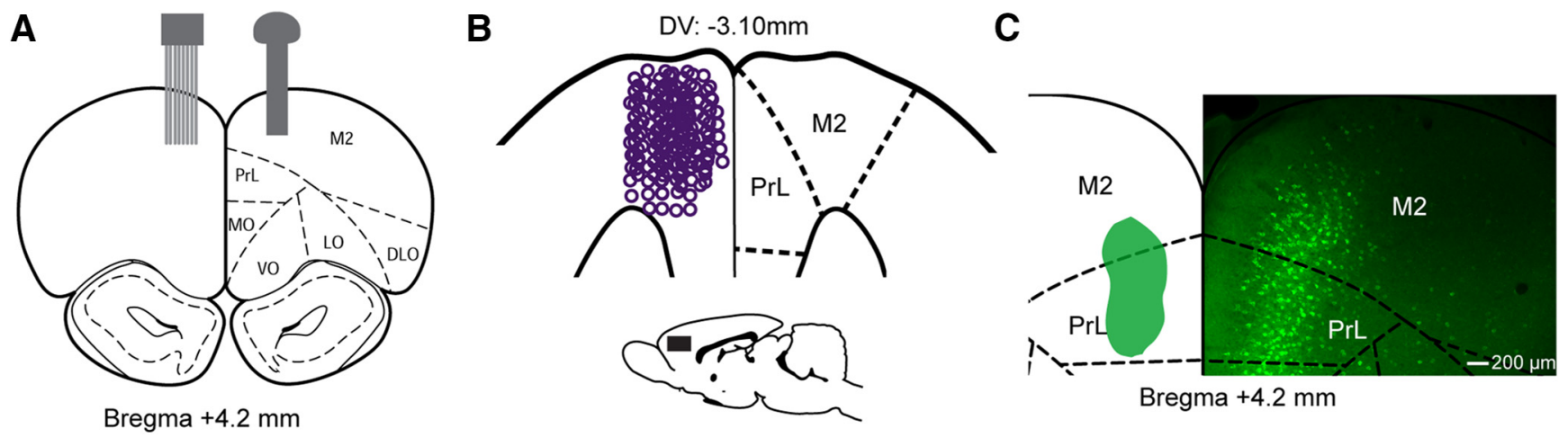

Figure 2. Neuronal recordings. $A$, All rats $(N=11)$ were implanted with a 16 -channel microwire array targeting the rostral MFC in one hemisphere. A subset of rats $(N=4)$ had a drug cannula implanted in the same cortical area in the opposite hemisphere. $\boldsymbol{B}$, Locations of recording sites are depicted on a horizontal section from the Paxinos and Watson (1997) atlas. All electrodes were placed within the prelimbic (PrL) and medial agranular (M2) regions. C, Validation of cross-hemispheric connections for this rostral MFC region. Cholera toxin subunit B with the AlexaFluor-488 reporter was injected in the rostral MFC of 5 rats. Green (left hemisphere) represents injection site spread. Neurons were labeled in the superficial layers in the opposite hemisphere (right).

sion 5 (Nex Technologies), we measured spike probabilities for all recorded MUAs around the higher- and lower-value licks, using $0.001 \mathrm{~s}$ bins. Spike probabilities were compared for the two lick values using a paired $t$ test (in $\mathrm{R})$. To measure spike-field coherence, we also used routines (sp2a_m) from Neurospec 2.0 (http://www.neurospec.org/) and analyzed bandpass filtered LFP (licking frequency \pm interquartile range) and the following parameters: segment power $=10$ (1024 points, frequency resolution: $0.977 \mathrm{~Hz}$ ), Hanning filtering with $50 \%$ tapering, and line noise removal for the LFPs at $60 \mathrm{~Hz}$. To measure spike-lick coherence, we used routines (sp2_m1.m) from Neurospec 2.0. The following parameters were used: segment power $=12(4096$ points, frequency resolution: $0.244 \mathrm{~Hz}$ ) and Hanning filtering with $50 \%$ tapering.

Validation of cross-hemispheric connectivity using retrograde tracers. The methods for stereotaxic surgery that are described above were used to make injections of cholera toxin subunit B in 5 rats to validate crosshemispheric connections within the rostral MFC, which have not been extensively studied in previous anatomical studies on the most rostral part of this cortical region (compare Gabbott et al., 2003; Hoover and Vertes, 2007). The cholera toxin subunit B had an AlexaFluor-488 reporter from Invitrogen and was injected at a $1 \%$ concentration and $400 \mathrm{nl}$ volume. A $10 \mu$ l glass Hamilton syringe and Narishige motorized microinjector (IMS-10) were used. A total of $10 \mathrm{~min}$ was allowed for diffusion after each injection. Brains were extracted using the methods described above for euthanasia and perfusion. Cortical slices were cut in the frontal plane using a freezing microtome and were imaged on fluorescent microscope (BX-51-F, Tritech Research) using an R1 camera and Ocular software from Qimaging.

\section{Results}

Multielectrode recordings in the shifting values licking task

To investigate the role of the frontal cortex in reward-related consummatory behaviors, we assessed licking behavior in rats while performing simultaneous recordings in the rostral MFC. We trained rats in the shifting values licking task (Parent et al., 2015a), in which they licked at a drinking spout to receive 0.025 $\mathrm{ml}$ of a liquid sucrose reward (Fig. 1A). The reward value of the fluid switched between higher (20\% sucrose w/v) and lower ( 2 or $4 \%$ ) levels every $30 \mathrm{~s}$. Experienced rats ( $>3$ training sessions) licked more for the high-value reward compared with the lowvalue reward (Fig. $1 B$; paired $t$ test between high-value and lowvalue licks: $\left.t_{(8)}=4.29, p=0.0026\right)$.

Eleven rats were implanted with multielectrode arrays (Fig. $2 A)$. The placement of electrodes is shown in Figure $2 B$. All electrodes were placed in the medial agranular and prelimbic areas. In 4 of the rats, a drug cannula was also implanted in the opposite hemisphere using the same stereotaxic coordinates. These animals were used to examine effects of reversible inactivation of the
MFC without shutting down local neuronal activity. To confirm that cross-hemispheric connections exist within the rostral MFC region, 5 rats were injected with cholera toxin subunit $B$ in the region where the neuronal recordings and reversible inactivations were made (Fig. 2C).

\section{Quantification of lick-entrained rhythmic activity}

We recorded 161 LFPs from the MFC in 11 rats as they ingested liquid sucrose in the shifting values licking task. An example of licking-related fluctuations in the LFPs is shown in Figure $3 A$. To measure entrainment between LFPs and the animal's licking, we bandpass filtered the LFPs around the licking frequency and used the Hilbert transform to extract the amplitude and phase of the perilick rhythm (Fig. 3B, left plots). The phase of LFPs was plotted using polar histograms (Fig. $3 B$, right plot).

To quantify relationships between licking and LFP phase, we used circular statistics to measure the consistency of the phase angles at the time of licks. We used Rao's spacing test for uniformity, which assesses the directional spread of circular data. Two LFPs did not have major power in the $6-12 \mathrm{~Hz}$ range and were excluded from this analysis. We plotted each electrode's location in MFC and shaded the locations by the intensity of the Rao statistic (Fig. 4A). Phase entrainment to the lick cycle was concentrated in three longitudinal zones within the prelimbic cortex (0-1 mm lateral to the midline), the medial agranular cortex ("M2") (1-1.5 mm lateral to the midline), and the border of the medial and lateral agranular cortex $(2-2.5 \mathrm{~mm}$ lateral to the midline). Examples of entrainment at four electrodes (from 4 different rats) located in each extreme of MFC space (rostral/lateral, rostral/medial, caudal/lateral, and caudal/medial) are shown in Figure $4 B$.

Remarkably, the LFPs as a population had a mean phase angle near 0 degrees (i.e., at the peak or trough of the neural oscillation) (Fig. 4C). This distribution was entirely distinct compared with population summaries based on surrogate data (i.e., "licks" derived from shuffled ILIs). Therefore, the MFC region as a whole showed a relatively similar phase that is suggestive of phase entrainment to the lick cycle.

To examine effects of licking on MFC across spectral frequencies, we used standard time-frequency analysis measures (EEGlab toolbox) (Delorme and Makeig, 2004). Lick-related changes in spectral power across frequencies between 0 and $100 \mathrm{~Hz}$ were measured using ERSP (Fig. 5A). Phase consistency at the times of the licks was measured using ITC (Fig. 5B). For each LFP record- 
A

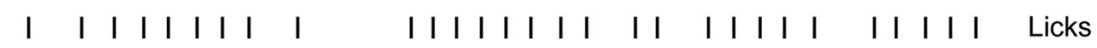

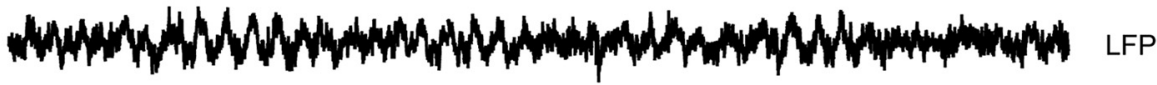
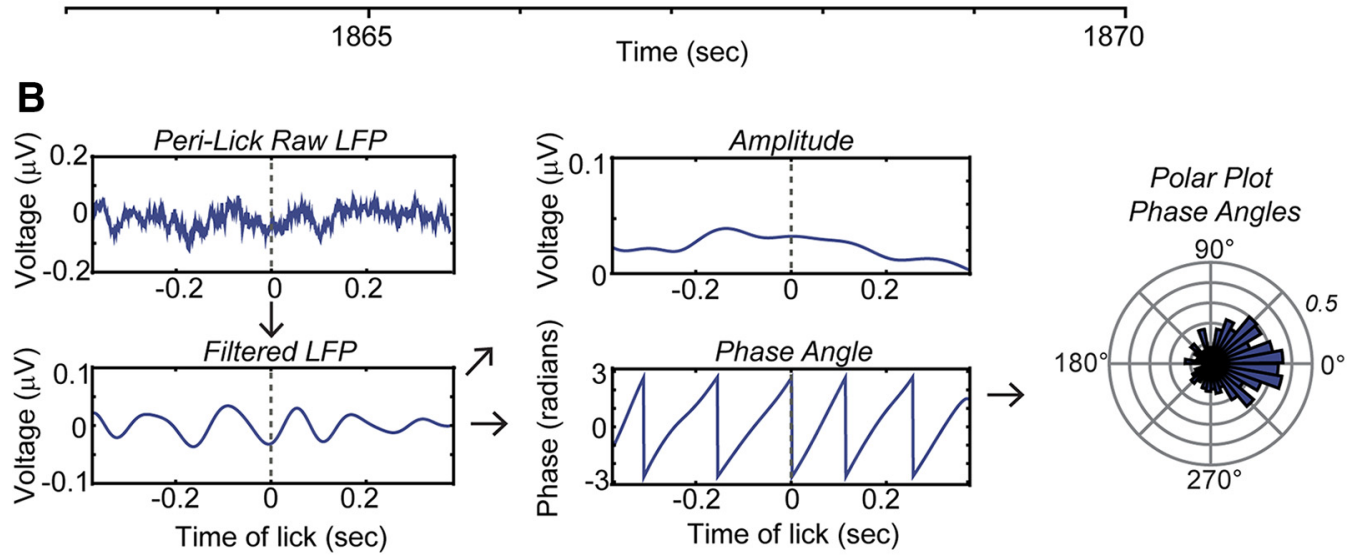

Figure 3. Neuronal activity in the MFC is entrained to the lick cycle. $\boldsymbol{A}$, An example of an LFP recording shows clear fluctuations at the times of licks (tick marks above the LFP). $\boldsymbol{B}$, Relationships between LFP signals and licking were assessed by bandpass filtering the LFPs near the licking frequency (defined by the interquartile range around the median ILI) and applying the Hilbert transform to measure the amplitude and phase of licking-related neuronal activity. Instantaneous phase was plotted using polar coordinates and analyzed with standard methods for circular statistics (Agostinelli and Lund, 2013). For details, see Materials and Methods.

A

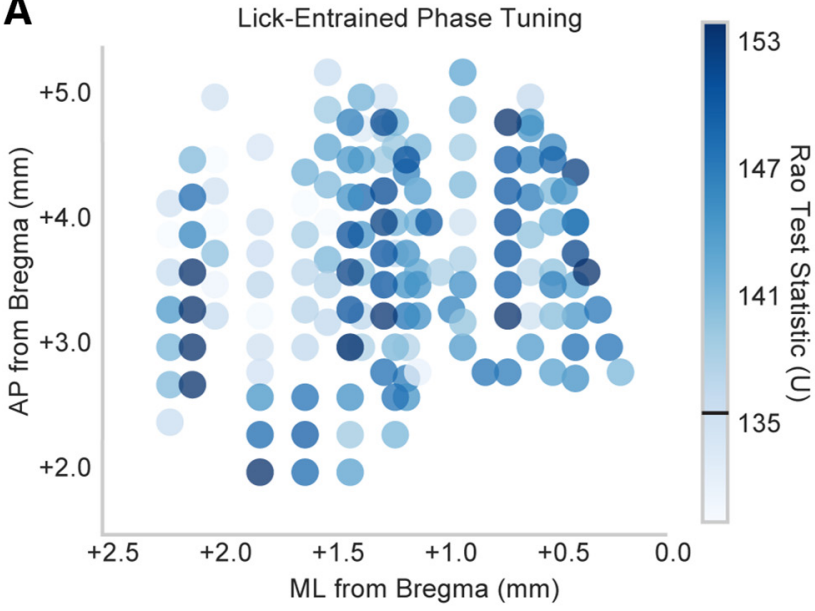

B

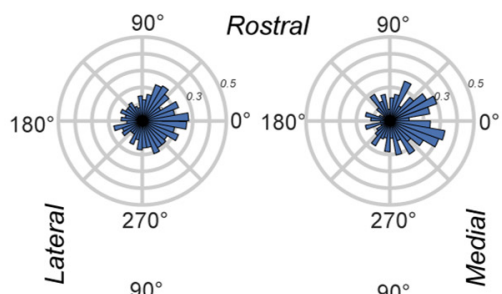

C Shuffled Data

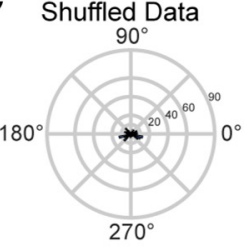

Observed Licks

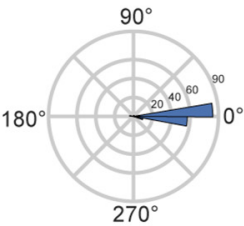

$N=159$ electrodes from 11 rats

Figure 4. Spatial distribution of entrainment to the lick cycle. $A$, Spatial plot of phase tuning using the test statistic from Rao's spacing test of uniformity showed no obvious topography of lick entrainment in the MFC. Individual electrode locations were plotted according to their location in reference to bregma ( $N=159$ electrodes). Recording sites were depicted as circles colored by the strength of their Rao test statistic $(U)$. Color bar represents values of $U$ from the 5 th-95th percentile range over all recording sites. Values above the black bar (near 135) were not uniform $(p<0.05$ ). $B$, Polar plots represent phase tuning examples from four spatial extremes of the graph in $A$. The most rostral/lateral (top left; $U=134.48, p>0.05$ ), rostral/medial (top right; $U=152.30, p<$ 0.001 ), caudal/medial (bottom right; $U=153.51, p<0.001$ ), and caudal/lateral (bottom left; $U=147.44, p<0.001$ ) electrodes were chosen. There was no drastic difference among the four locations with regard to phase tuning. C, Group summaries of the mean phase angle at the time of licking from all 11 rats reveal significant phase tuning toward 0 degrees (i.e., peak or trough of the rhythm). These results were compared with phase angles measured from surrogate data (shuffled ILIs), which did not show evidence for significant phase entrainment.

ing, we measured the frequency with the highest level of ERSP and ITC. Most LFPs (127 of 161) showed peak ERSP in the delta range (1-4 Hz). Most LFPs (104 of 161) showed peak ITC near the licking frequency, between 5.8 and $7 \mathrm{~Hz}$. Some LFPs showed peak ITC near $8 \mathrm{~Hz}(N=27)$ or between 8 and $12 \mathrm{~Hz}(N=28)$. The LFPs with higher frequencies for peak ITC were recorded on common arrays, and our finding of variability among peak ITC frequencies might reflect differences in cortical layer or field, but we were unable to address these issues completely in the present study. The vast majority of LFPs (159 of 161) showed peak ITC at the time of licking between 5.8 and $12 \mathrm{~Hz}$, and so we describe this frequency range as $6-12 \mathrm{~Hz}$ theta throughout the manuscript.

To determine whether the spectral ERSP and ITC measures were synchronous with the lick cycle, or simply elevated during periods of licking but not time-locked to the actual licks (asynchronous), we created surrogate data by shuffling ILIs. This analysis provided evidence for both measures, ERSP and ITC, being elevated at the licking frequency in shuffle-corrected plots of ERSP and ITC (Fig. 5A, $B$, right panels). This finding, together with the analysis using circular statistics described above, is strong evidence for an entrainment of $6-12 \mathrm{~Hz}$ theta activity in the MFC being entrained to the lick cycle.

As a previous study reported that consummatory-related activity in the MFC is sensitive to satiety (Bouret and Richmond, 2010; for related findings on the rodent orbitofrontal cortex, see also de Araujo et al., 2006), we examined whether there were cross-session effects within our datasets that could reflect effects of satiety. We checked for stability in licking-related ERSP and 


\section{Event-Related Spectral Power (ERSP)}
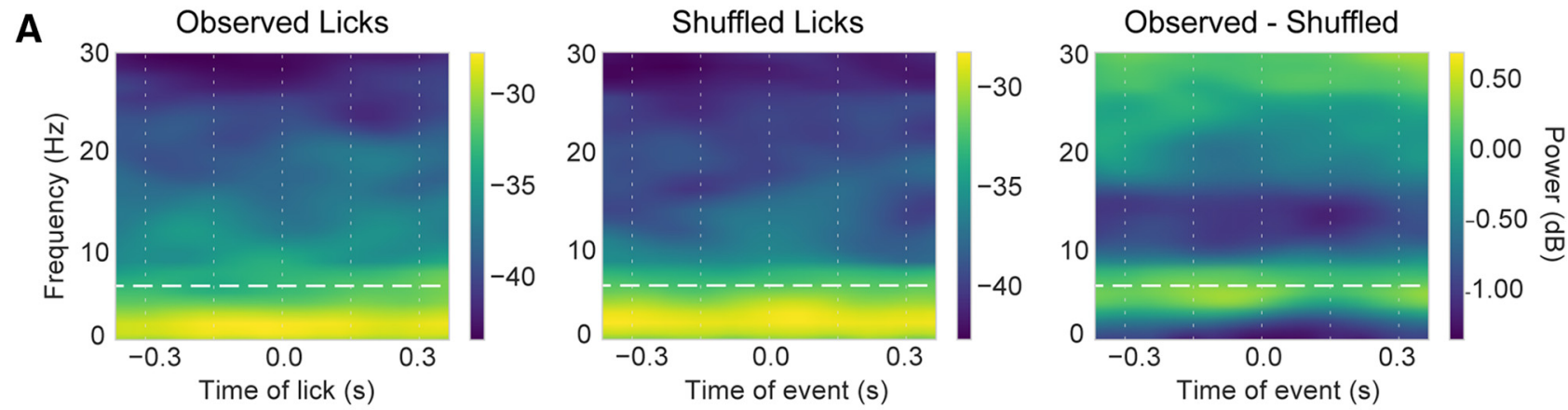

Inter-Trial Coherence (ITC)
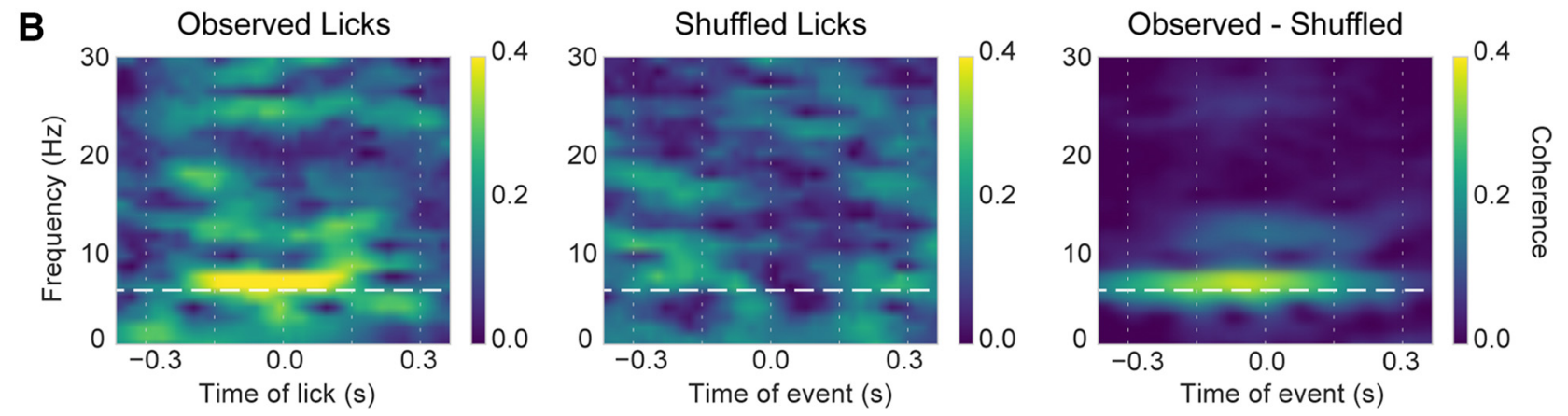

Figure 5. Time-frequency analysis of lick-entrained LFP data. ERSP (top) and ITC are shown for a typical LFP recording aligned to the time of licking in the behavioral task. White horizontal dashed line indicates the median licking frequency. White vertical dashed lines indicate the median ILIs. ERSP and ITC measures were computed using observed licks (left) and surrogate data (middle), created by shuffling ILIs. A, Persistent elevated ERSP was notable at very low frequencies ( $\sim 2 \mathrm{~Hz}$, or delta) for both the observed (top left) and shuffled (top middle) events (i.e., was not entrained to the lick cycle). Subtraction of the shuffled ERSP matrix from the observed ERSP matrix revealed elevated power at the licking frequency (horizontal dashed line). $\boldsymbol{B}$, ITC was apparent near the licking frequency over a period of 2 lick cycles for the observed licks (lower left), but not the shuffled licks (bottom middle). Subtraction of the shuffled ITC matrix from the observed ITC matrix revealed elevated power at the licking frequency (horizontal dashed line).

ITC levels over the behavioral sessions by dividing licks into 10 blocks with either equal numbers of licks or equal amounts of time in the session. Peak levels of ERSP and ITC between 4 and $12 \mathrm{~Hz}$ and within one ILI around each lick were measured over the blocks. No obvious pattern indicating satiation was apparent in this analysis (for ITC results, see Fig. 6). This analysis suggests that entrainment of MFC activity to the lick cycle does not reflect satiety or other cross-session factors.

\section{Theta entrainment to licking develops with experience}

In a subset of 3 rats, we recorded neuronal activity as the animals learned to perform the shifting values licking task (Fig. 7). Over the first $4 \mathrm{~d}$ of training, the rats showed increased licking when the higher-value reward was available relative to licking for the lower-value option (Fig. 7A). Repeated-measures ANOVA found a main effect of reward value on licking $\left(F_{(1,14)}=32.20, p=5.7 \times\right.$ $\left.10^{-5}\right)$. Tukey's post hoc test found evidence for a difference between the number of licks for the high-value versus low-value reward in Session 4 ( $p=0.013)$, but not Session $1(p=0.935)$. Median ILIs were reduced from Session 1 to Session 4 (Wilcoxon rank-sum test from 3 rats individually: $p<10^{-6}$ ), but this effect was relatively minor. The average median ILI in Session 1 was $0.174 \pm 0.133 \mathrm{~s}$. The average median ILI in Session 4 was $0.153 \pm$ $0.026 \mathrm{~s}$. This difference resulted in an increase of no more than $1.12 \mathrm{~Hz}$ in the average licking frequency between Session 1 and Session 4.

Entrainment to licking developed over the training sessions, with clear lick-related oscillatory patterns apparent in the LFPs by the fourth training session (Fig. 7B). ERPs were larger for licks that delivered the higher-value sucrose reward (Fig. $7 B$, blue lines). The spectral content of the signals was evaluated using the same ERSP and ITC analyses used in Figures 5 and 6. Notably, there was a distinction between high-value and low-value phaselocking to the onset of licking evident in LFP data from Session 4, but this signal was not apparent during Session 1 (Fig. 7C). To capture effects of the different sucrose concentrations on the LFPs, we calculated a "value index" for each electrode (Fig. 7D). This index was derived from difference between the peak ITC level for the high- and low-value licks divided by the peak ITC level for the high-value licks. All electrodes from all rats showed an increase in this index, a result that indicates increased differences in phase-locking for two amounts of reward over the period of training (paired $t$ test: $t_{(39)}=-12.085, p<10^{-6}$ ).

To further measure changes in the signals associated with the two reward values over sessions, we performed a repeatedmeasures ANOVA with the peak ITC values as the dependent variable and the values of the licks and the training sessions as predictors. This analysis found a significant interaction between session and value $\left(F_{(1,155)}=22.43, p<10^{-6}\right)$, and Tukey's post hoc test found evidence for differences between Session 1 versus Session 4 high-value lick ITC values $(p=0.0016)$. Although these analyses found evidence for significant difference between ITC levels for the high- and low-value licks in Session $1(p=0.0093)$, the difference between ITC levels was much greater in Session 4 $\left(p<10^{-6}\right)$.

We also assessed changes in LFP power by performing the same type of repeated-measures ANOVA, using peak ERSP values as the dependent variable. There was a significant interaction 


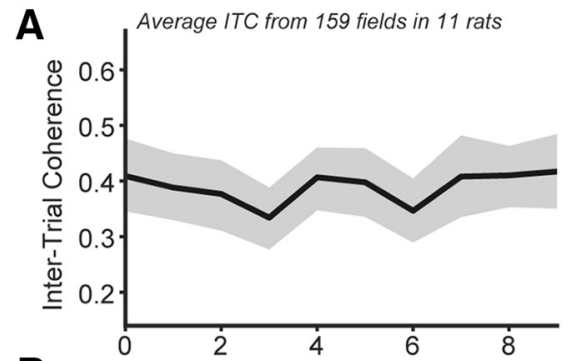

B

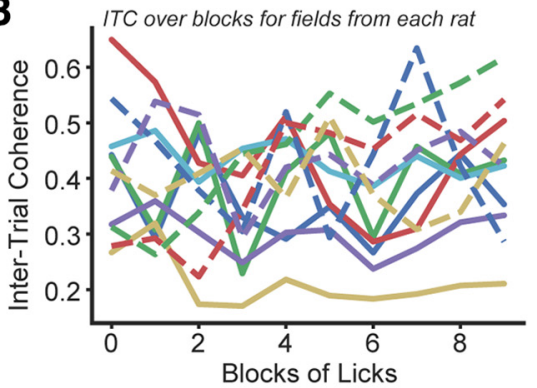

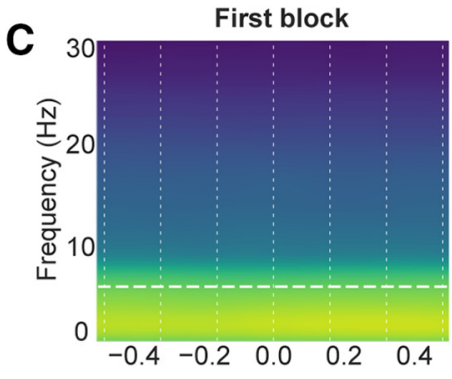

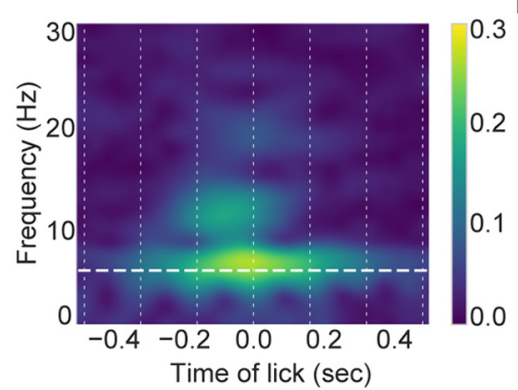

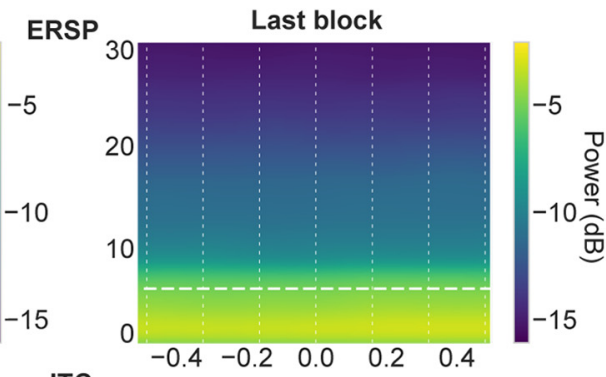

ITC

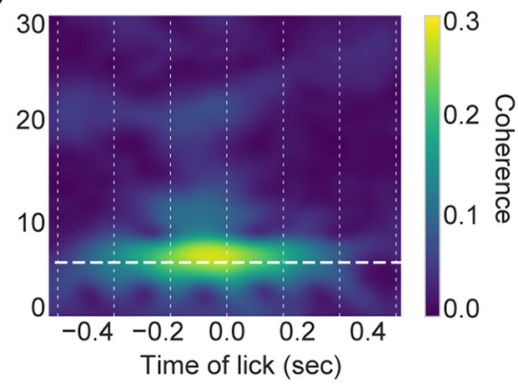

Figure 6. Entrainment was stable over the 30 min test sessions. Sessions were split into 10 blocks with equal numbers of licks, and peak ERSP and ITC were measured in the theta frequency range $(6-12 \mathrm{~Hz})$ over the ILI before and after each lick. $A$, Group average of peak ITC showed no evidence for a change in this measure over the datasets. Similar results were obtained for ERSP (data not shown). $\boldsymbol{B}$, Traces for peak ITC from each of the 11 rats. C, Grand average of ERSP and ITC for all LFPs in the first and last block. Together, these results suggest that entrainment of MFC LFPs to the lick cycle was not sensitive to cross-session factors, such as satiety.

A

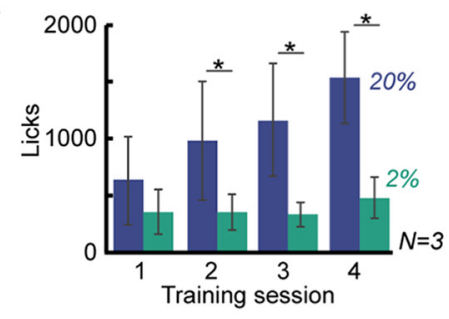

C
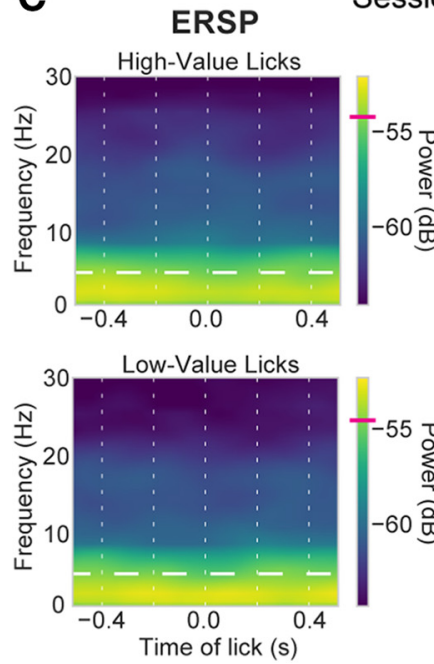

B

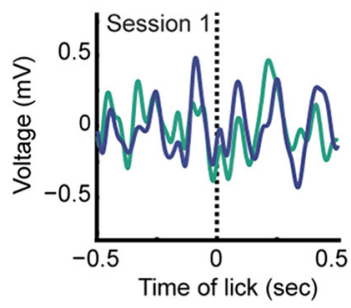

ITC
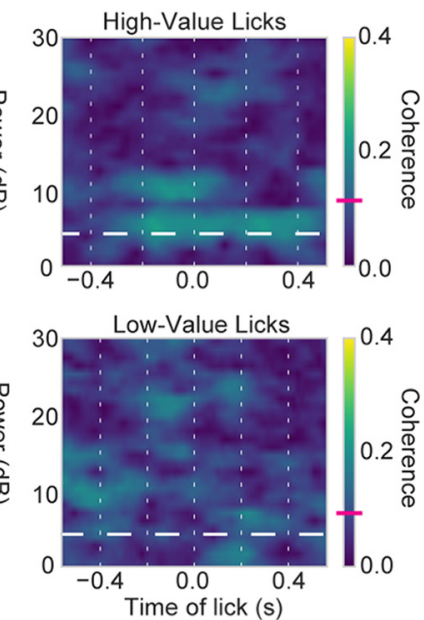

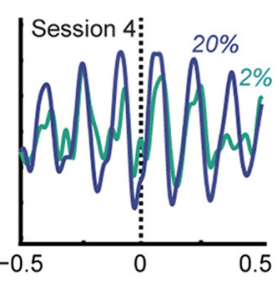

ERSP
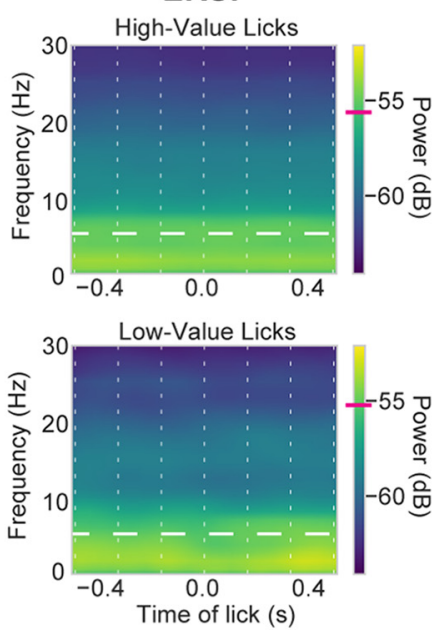

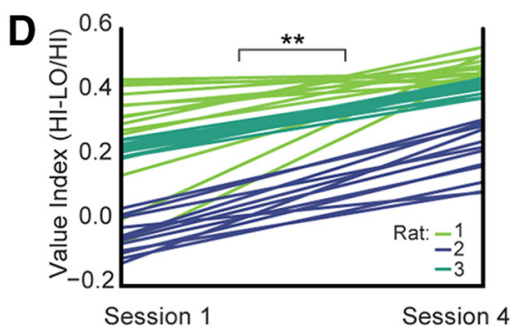

Session 4

ITC

High-Value Licks
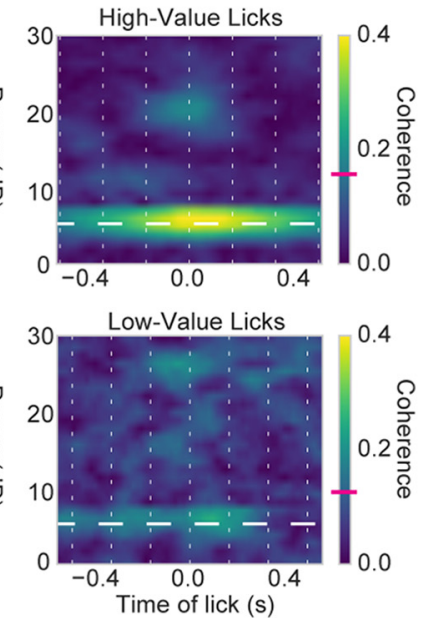

Figure 7. MFC theta entrainment to licking develops with experience. $\boldsymbol{A}$, Recordings were made in a subset of 3 rats as they learned the behavioral task. The rats showed increased licking for the high-value sucrose compared with the low-value sucrose after the first training session and the relative difference in licking increased over the first four training sessions. $\boldsymbol{B}$, Neuronal entrainment to the lick cycle developed with experience in the task. For example, ERPs increased in size and apparent rhythmicity between the first and fourth training session. Blue represents higher-value $20 \%$ sucrose. Green represents lower-value 2\% sucrose. C, Increased entrainment to the lick cycle was also apparent in ITC, which was not apparent in Session 1 and specific to licks that delivered high-value sucrose in Session 4. White vertical lines indicate average ILIs across the session. White horizontal dashed line indicates average licking frequency across the session. Magenta ticks in the color bars indicate average ERSP or ITC at the median licking frequency. $\boldsymbol{D}$, To capture differences in ITC values for the two types of licks across all recordings, we used a value index, defined as ((ITC-HI - ITC-LO)/ITC-HI). The index was based on the peak ITC values in a temporal window ranging from $1 \mathrm{lLI}$ before lick onset up to $50 \mathrm{~ms}$ after the lick and for all frequencies between 4 and 12 $\mathrm{Hz}$ ("theta"). As shown in the parallel line plot, in which each line indicates an LFP recording from a distinct electrode, this index was larger in Session 4 compared with Session 1 (paired $t$ test: $\left.t_{(39)}=-12.085, p<10^{-6}\right){ }^{*} p<0.05,{ }^{* *} p<10^{-6}$. 
A
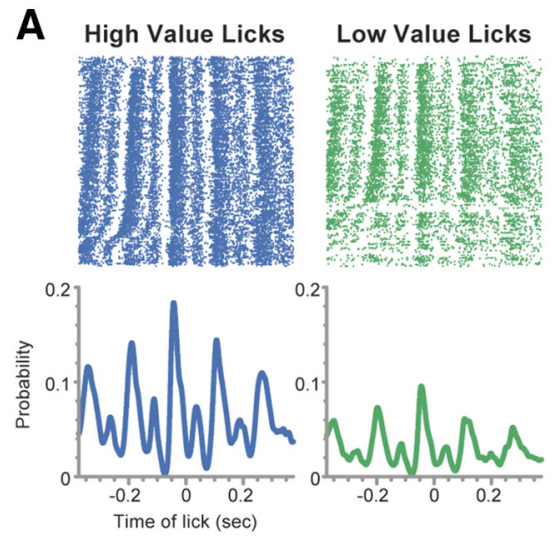

B

B

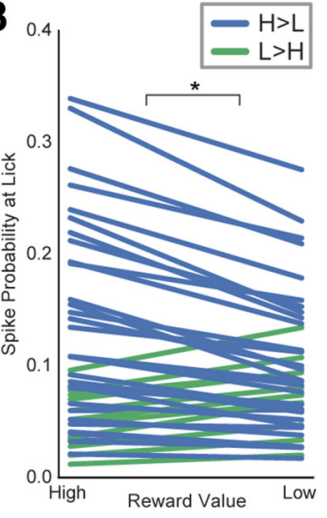

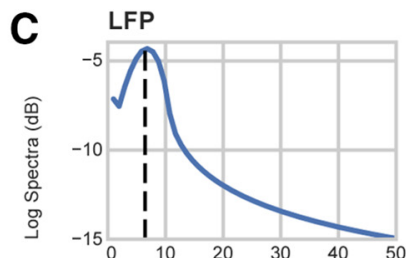
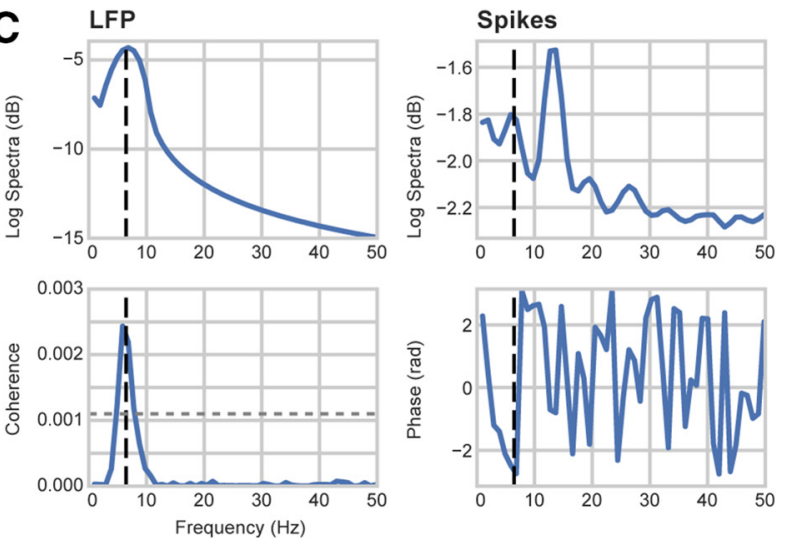

Figure 8. Coherence between spikes and licks reflects reward information. $A$, MUA was entrained to the lick cycle. Blue represents high-value licks. Green represents low-value licks. Rasters were sorted by the latency to the last lick before the lick at time 0 , with the shortest preceding intervals at the top of the raster. The high-value licks were subsampled for this plot so that neural activity could be compared for the same number of total licks (at time 0). Perievent histograms (bin: $1 \mathrm{ms,}$ 10-point Gaussian smoothing), below the raster plots, denote the probability of spiking around the times of the licks. $\boldsymbol{B}$, Group summary for spike probability at times of higher- and lower-value licks. Blue lines indicate higher spike probability for the higher-value sucrose. Green lines indicate higher spike probability for the lower-value sucrose. Spike probability was higher at the times of the higher-value licks compared with times of the lower-value licks (paired $t$ test: $t_{(43)}=3.78, p<0.001$ ). A total of 33 of the 44 MUA recordings showed higher spike probabilities for the higher-value licks. C, Spike-field coherence found that all 44 MUA recordings were entrained to the LFP fluctuations that encoded reward information. Power spectra are shown in the top row for example LFP and MUA recordings. Peak power was near the licking frequency (black dashed line) for the LFP. The main peak for the spike train was in the low $\beta$ range (12-15 Hz), and a second peak was at the licking frequency. Coherence between these signals (bottom left plot) was found at the licking frequency $(5.96 \mathrm{~Hz})$, at a level approximately twice the $95 \% \mathrm{Cl}$. The phase between the spikes and fields at the licking frequency (bottom right plot) was near $-\pi$, suggesting that the spikes and fields had an antiphase relationship. ${ }^{*} p<0.001$.

between session and reward value $\left(F_{(1,155)}=9.991, p=0.0019\right)$. Tukey's post hoc analyses showed a difference in power from Session 1 to Session 4 high-value licks $\left(p=3.5 \times 10^{-4}\right)$, as well as power for Session 4 high- and low-value licks $\left(p=4.3 \times 10^{-5}\right)$. There was no difference in power between Session 1 high-value and low-value licks $(p=0.99)$. These findings are evidence for learning-dependent changes in the theta entrainment by the event-related power (ERSP) and phase (ITC) to the lick cycle.

\section{MFC spike activity is entrained to the lick cycle}

Simultaneous recordings of spike activity in the 3 rats tested during the final learning session showed evidence for spike entrainment to the lick cycle (Fig. $8 A$ ). The probability of spiking at the times of licks was $<0.1$ for all isolated single units. Therefore, we reisolated MUA $(N=44)$ for the analyses reported here and measured the probability of spiking at the times of the higherand lower-value licks. Spikes were more likely to be coincident with the higher-value licks $(0.113 \pm 0.013$, mean $\pm \mathrm{SD})$ compared with the lower-value licks $(0.092 \pm 0.009)$ for 33 of 44 spike recordings (Fig. $8 B$; paired $t$ test: $t_{(43)}=-3.78, p=0.00047$ ).

Spike-lick coherence was used to further analyze synchronization between spikes and the higher- and lower-value licks. Results were complicated (and thus not shown graphically), with spikes having major peaks at various frequencies in the $\beta$ and $\gamma$ ranges, and spike-lick coherence often being significant in those ranges. A total of 33 of 44 units (75\%) fired in phase with the highervalue licks. Nineteen units (43\%) fired in phase with licks that delivered the lower-value fluid. Over all recordings, the level of spike-lick coherence was greater for the higher-value licks compared with the lower-value licks (paired $t$ test: $t_{(43)}=4.6, p<0.001$ ).

A much simpler result was obtained by using spike-field coherence to examine synchronization between the spikes and fields (Fig. 8C). All 44 MUA recordings exhibited significant levels of spike-field coherence at the licking frequency (Fig. $8 C$, bottom left plot). Interestingly, phase was uniformly near $-\pi$ for these datasets (Fig. 8C, bottom right plot), indicating that spikes and fields were explicitly out of phase (antiphase). Together, these results suggest that the lick-entrained theta rhythmic activity, as measured in the LFPs, was also manifest in lick-entrained spike activity within the rostral MFC.

\section{Reward context, not reinforcement, drives licking-related theta entrainment}

The signals described above could reflect the expected reward magnitude (van Duuren et al., 2007) and/or the taste or fluid properties of the ingested solutions (Jezzini et al., 2013). To examine these issues, we modified the shifting values licking task to include a $2 \mathrm{~s}$ period of nonreinforced licking between periods of reward delivery (Fig. 9A). This procedure resulted in rats continuously licking at the spout during the nonreinforced blocks of the task. Six rats were tested in the procedure with neuronal recordings, and the occurrence of licking in each context (licks per unit time) was analyzed by calculating the number of licks in each context divided by the actual time spent in each context across the session (Fig. 9B). All rats continued to lick more during these nonreinforced blocks when they could receive the high-value fluid compared with when they could receive the low-value fluid $\left(t_{(5)}=5.20, p=0.0003\right.$ for all high-value context licks against all low-value context licks; $t_{(5)}=5.63, p=0.0025$ for nonreinforced high-value context licks vs nonreinforced low-value context licks; $t_{(5)}=3.31, p=0.0213$ for reinforced high-value context licks vs reinforced low-value licks).

LFP signals synchronized to reinforced and nonreinforced licks were similar, with the main differences between high-value licks and low-value licks still evident, despite the rats not being rewarded during the nonreinforced blocks. Figure $9 C, D$ shows group summaries of the differences in peak ERSP and ITC values at the onset of the reinforced and nonreinforced high-value licks. (We chose to focus on the high-value licks for the analyses due to the increased number of high-value licks emitted during the task, although low-value licks also show the same effect.) There were no major differences in peak ERSP levels for reinforced and nonreinforced licks $\left(F_{(1,359)}=2.52, p=0.11\right)$, which is also evi- 
A

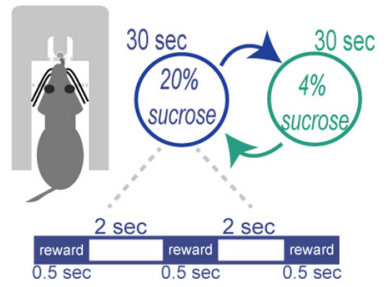

E
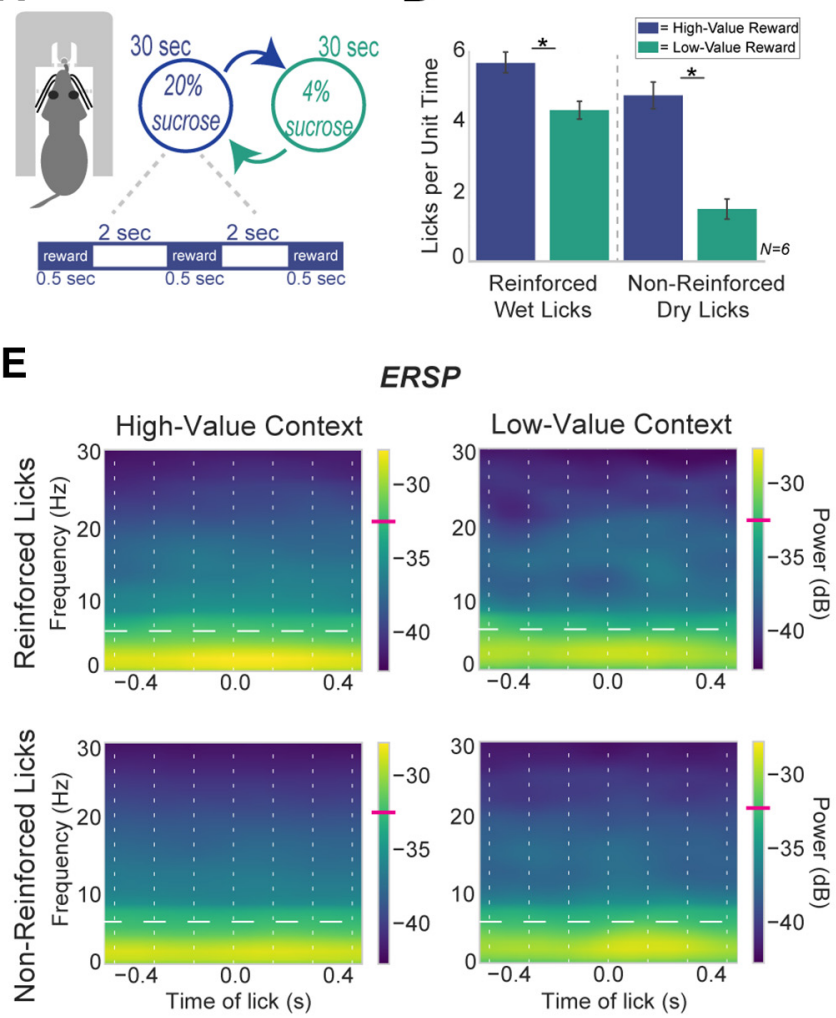

ERSP
C

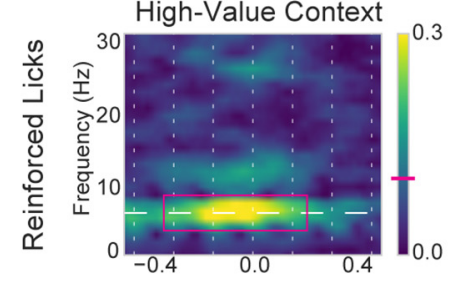

ITC
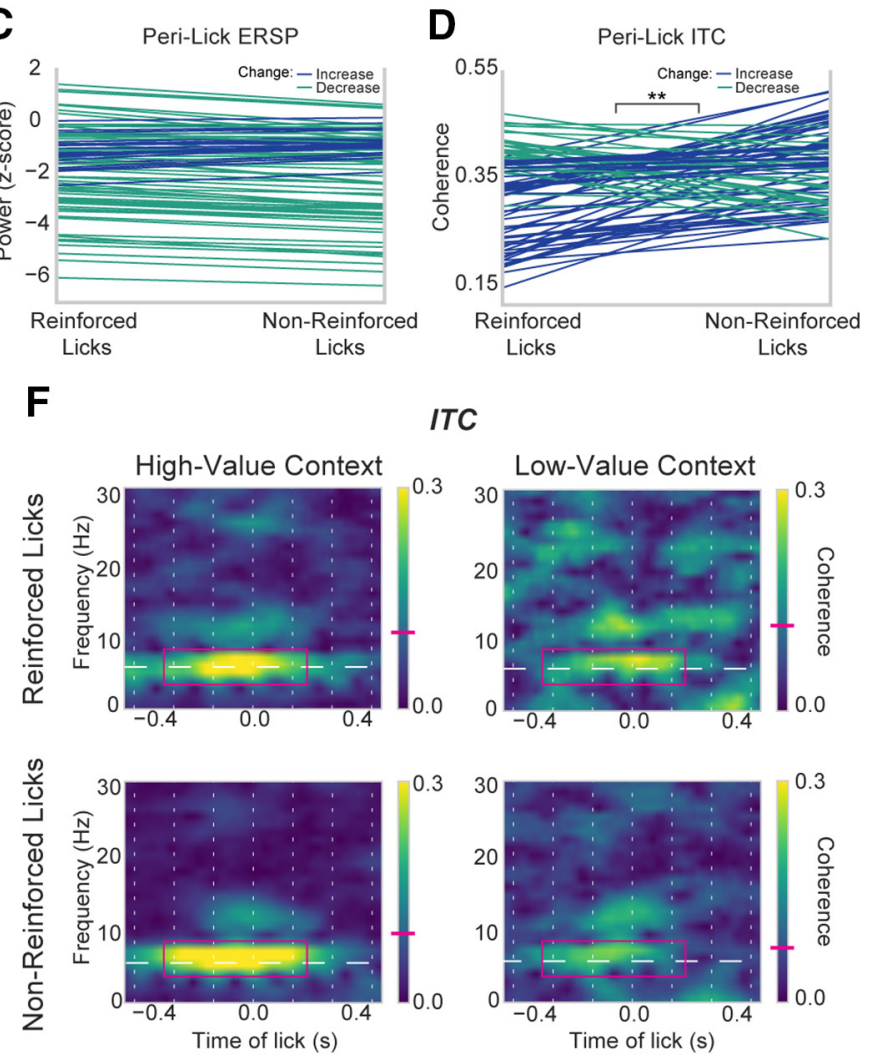

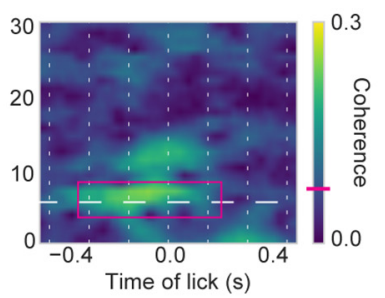

Figure 9. Reward context, not reinforcement per se, drives reward signaling. $\boldsymbol{A}$, The shifting values licking task was modified to include a $2 \mathrm{~s}$ period between reward deliveries. This period allowed for nonreinforced licks (dry licks at the spout) to be recorded within the 30 s states of high or low-value sucrose availability. $B$, Group summary ( $N=6$ ) of licks per unit time (total licks emitted in each context divided by time spend in each context). This measure revealed that rats licked less in the nonreinforced lower-value blocks compared with the other blocks. $\boldsymbol{C}$, Peak ERSP values for reinforced versus nonreinforced licks during the high-value blocks. Lines are colored by their direction (increase or decrease in power). There was no difference in power for reinforced versus nonreinforced licks $\left(F_{(1,359)}=2.52, p=0.11\right)$. D, Peak ITC values for reinforced versus nonreinforced licks during the high-value blocks. The majority of LFPs showed increased phase-locking to nonreinforced licks (blue lines), whereas electrodes from 2 rats show a slight decrease in phase-locking for nonreinforced licks (green lines). Overall group summaries show an increase in phase-locking for the nonreinforced licks $\left(F_{(1,359)}=31.94, p<10^{-6}\right) . \boldsymbol{E}, \boldsymbol{F}$, Example of time-frequency analysis of an LFP from a rat that showed decreased ERSP and ITC (magenta box) when the rat licked in the lower-value context. ITC was higher near the licking frequency when the higher-value reward was available, regardless of whether the licks were reinforced or not. Horizontal white lines indicate the within-session licking frequencies. Vertical white lines indicate the ILIs for each session. Magenta ticks in the color bars represent average ERSP or ITC at the median licking frequency. ${ }^{*} p<0.05,{ }^{* *} p<10^{-6}$.

dent in the spectral plots from an example LFP recording shown in Figure 9E.

However, the majority (60 of 91) of the electrodes (from all rats) showed increases in ITC phase-locking values for the nonreinforced high-value licks (Fig. 9D). We performed a repeatedmeasures ANOVA with factors for lick type (reinforced or nonreinforced) and reward value (high or low) with peak ITC values as the dependent variable. This analysis found evidence for a significant interaction between lick type and reward value $\left(F_{(1,359)}=31.94, p<10^{-6}\right)$. The nonreinforced licks had slightly greater ITC values at the onset of licking (high-value reinforced licks $=0.48, \mathrm{SD}=0.069$; high-value nonreinforced licks $=0.51$, $\mathrm{SD}=0.063$ ), which was also confirmed using Tukey's post hoc test (reinforced vs nonreinforced high-value licks, $p=0.0002$ ). Spectral plots, shown in Figure $9 F$, revealed modest increases in phase-locking for the nonreinforced high-value licks, and minimal differences in the phase-locking for the reinforced versus nonreinforced low-value context licks.

These findings cannot easily be explained by how often the rats licked in each task context. If engagement in licking (vigor or intensity) explained the pattern of neural results, then we would have expected to find elevated ITC levels when the rats received liquid sucrose as well as when they made nonreinforced licks in the high-value blocks. However, ITC levels were not elevated when rats licked for the lower concentration of sucrose. We ex- amined two other behavioral measures of licking to determine whether the differences in ITC levels could be accounted for by a behavioral measure from the task. First, we examined the licking frequency (based on ILIs) but found no differences between median ILIs (Mann-Whitney test: $U_{5}=-0.3202, p=0.7487$ ) and the interquartile ranges for the ILIs $\left(U_{5}=-1.4412, p=0.1495\right)$ in the higher and lower reward contexts, findings that discount the role of the frequency of licking in explaining the ITC results. By contrast, when we examined the persistence of licking, using bout analysis (as in Parent et al., 2015a, b), we found clear differences in the duration of licking bouts in the higher $(5.8003 \pm$ $0.9278 \mathrm{~s})$ and lower $(1.6969 \pm 0.3932 \mathrm{~s})$ reward contexts $\left(U_{5}=\right.$ $2.5621, p=0.0104)$. Bouts were on average $\sim 3.4$ times longer in the higher-value contexts. As such, the differences in ITC levels across the higher and lower reward contexts were associated with the persistence with the rats licked in the two behavioral contexts, but not the vigor or frequency at which they licked. These findings suggest that reward expectation, rather than the properties of the delivered fluids, drives reward signaling in the rostral MFC.

\section{Reward signaling depends on the MFC}

Having established the MFC as signaling reward information through lick-entrained neuronal rhythms, we performed a reversible inactivation study to determine whether the rhythmic activity is generated by neurons in the MFC. (Alternatively, the 
A

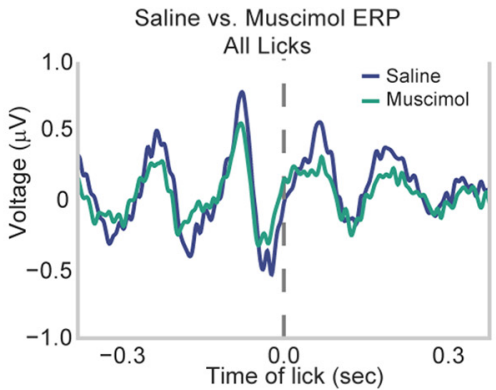

B

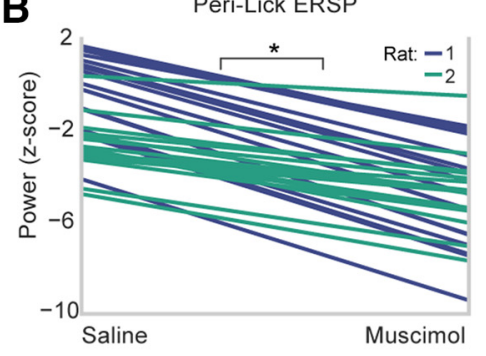

C

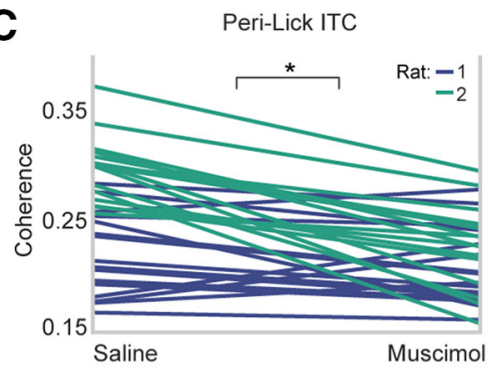

D
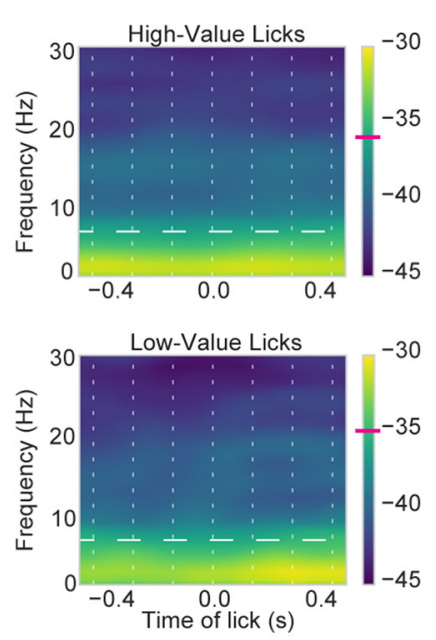

ERSP
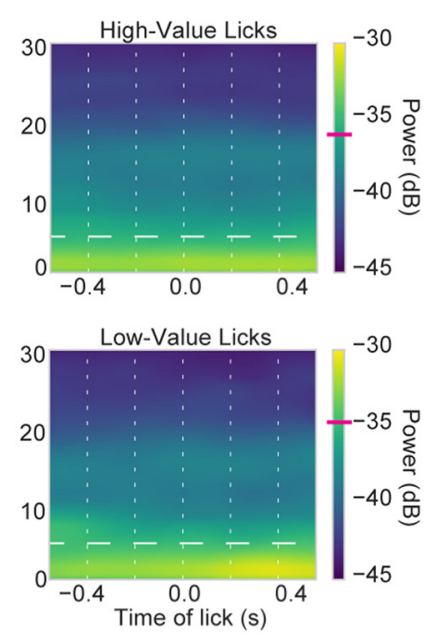

E
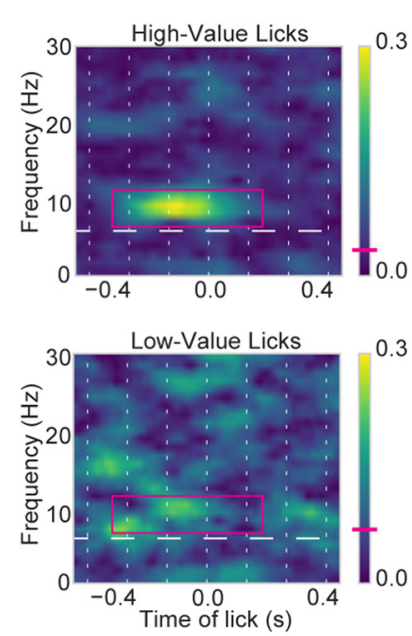

ITC
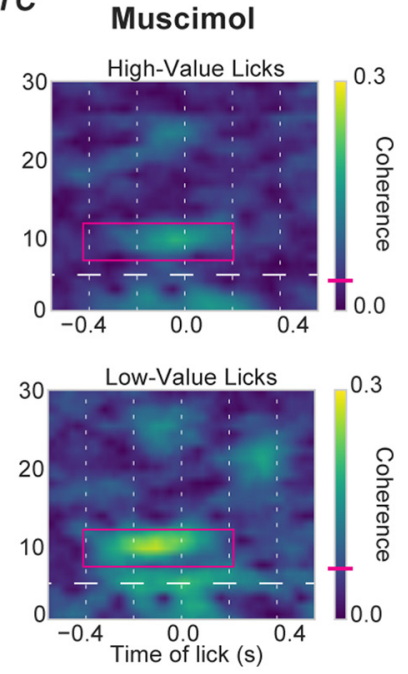

Figure 10. Reward signaling depends on neuronal activity in the MFC. Rats were tested with an electrode array in one hemisphere and an infusion cannula in the other, which was used to infuse either PBS or muscimol. $\boldsymbol{A}$, ERPs from the saline (blue line) and muscimol (yellow line) sessions showed a similar overall time course around the licks. $\boldsymbol{B}$, All electrodes showed a decrease in peak ERSP at the licking frequency for higher-value licks during the muscimol sessions compared with the PBS sessions $\left(F_{(1,123)}=96.09, p<10^{-5}\right)$. C, Likewise, there was a reduction in peak ITC at the licking frequency for 28 of 32 electrodes $\left(F_{(1,123)}=18.17, p=3 \times 10^{-5}\right)$. D, E, Example of time-frequency analysis. Effects were specific to licks for the high-value reward. Horizontal white lines indicate the within-session licking frequencies. Vertical white lines indicate the ILIs for each session. Magenta ticks in the color bars represent average ERSP or ITC at the median licking frequency. ${ }^{*} p<10^{-5}$.

signals could be generated elsewhere and broadcast to the MFC.) We implanted 4 rats with a multielectrode array in one hemisphere and a drug infusion cannula to allow for infusing muscimol in the MFC in the opposite hemisphere (Fig. 2A). Cross-hemispheric inactivation was done to allow for recording distant effects of MFC perturbation, and not the effects of a local shutdown of neuronal activity. Two of these rats had precisely aligned electrode arrays and drug cannula (same cytoarchitectural area and layer). Two other rats were not precisely aligned (e.g., cannula in superficial layers and array in deep layers), and electrophysiological data from those animals were not considered further. In all 4 rats, we did not observe any major behavioral change in the number of licks emitted after the unilateral muscimol infusions. There was a marginal decrease in the overall ILIs under muscimol (Mann-Whitney $U$ test, $p<0.05$ ). There was no difference in bout durations for the high- or low-value licks between the saline and muscimol sessions ( $p>0.05$ for all comparisons, MannWhitney $U$ test). This is in contrast to our previous study with bilateral inactivations (Parent et al., 2015a), which clearly alter performance of the task, including the persistence of licking bouts. The lack of behavioral effects of muscimol allowed us to assess potential electrophysiological changes without overt effects of the inactivations on the animals' licking behavior.

In the 2 rats with aligned electrode arrays and drug cannulas, LFP activity during muscimol inactivations was dramatically altered. Muscimol infusions slightly decreased ERPs synchronized to licking (Fig. 10A) and dramatically decreased ERSP at the lick- ing frequency (Fig. 10B, all electrodes plotted from 2 rats). This was confirmed in the spectral plots, shown from one example electrode from 1 rat (Fig. 10D). A repeated-measures ANOVA on peak ERSP values around the onset of licking found evidence for decreased power at lick onset between the saline and muscimol sessions $\left(F_{(1,123)}=96.09, p<10^{-6}\right)$. Muscimol infusions also decreased the lick-entrained phase-locking in the theta frequency range. As seen in Figure 10C, 28 of 32 electrodes showed decreased phase-locking around the onset of licking. A repeatedmeasures ANOVA found evidence for difference in ITC values for the saline and muscimol sessions $\left(F_{(1,123)}=18.17, p=3.9 \times\right.$ $\left.10^{-5}\right)$. Spectral plots from an example electrode (Fig. 10E) show diminished phase coherence in the theta frequency range for the high-value licks. The decrease in phase-locking therefore disrupted the previously evident differential signaling of high- and low-value sucrose rewards. Together, this inactivation study established that the theta-entrained activity described throughout this study, and also reported for single-value water rewards in Horst and Laubach (2013), are generated by neurons in the rostral MFC.

\section{Discussion}

Dynamics of reward-related activity in the MFC

The main idea of this study was that rodents lick to consume rewarding fluids, and reward information is therefore likely to be encoded in a dynamic manner, in phase with the rewarded actions. Initial evidence for this idea was reported by Horst and 
Laubach (2013), who found MFC neurons that were selectively activated when thirsty rats initiated bouts of licking to consume water. The present study was designed to further examine the dynamics of reward-related activity in the MFC as rats ingested varying levels of liquid sucrose during an MFC-dependent incentive-contrast licking task (Parent et al., 2015a, b). Multielectrode recordings were made in the rostral MFC as rats consumed relatively higher- and lower-value rewards that were available in alternating periods of $30 \mathrm{~s}$ (Figs. 1,2). We found that the entrainment of MFC spikes and field potentials to the animals' lick cycle varied with the concentration of liquid sucrose that was ingested (Figs. 345-6, 8). These signals were distributed broadly throughout the rostral part of the MFC (Fig. 4A). Spectral methods showed that these effects were selective to the 6-12 $\mathrm{Hz}$ theta range, which also encompasses the animals' licking frequency (Fig. $7 C$, right plots). We further examined whether theta-entrained activity to the lick cycle is stable across the testing sessions (Fig. 6), develops with experience (Fig. 7), does not depend on the presence of the rewarding fluids (Fig. 9), and depends on processing by MFC neurons (Fig. 10).

The differential expression of lick-entrained MFC theta might reflect the reward value of the ingested fluids and/or the vigor or persistence with which rats lick to consume the fluids. As the rostral MFC is known to have extensive interconnections with the "gustatory" insular cortex (Gabbott et al., 2003), MFC reward coding might reflect differences in the tastes or fluid properties of the sucrose solutions. Alternatively, the rostral MFC projects to a number of orolingual motor areas (Yoshida et al., 2009; Haque et al., 2010; Iida et al., 2010) and could mediate cortical control over the vigor (intensity per unit time) or persistence (bout structure) of licking. To examine these issues, we modified the task to have periods of nonreinforced licking between each reward delivery (Fig. 9). If the presence of fluids drives MFC signaling, then differences in MFC activity should only occur when the animals were actively ingesting the fluids. Surprisingly, this experiment revealed that the theta-entrained activity persisted beyond the period of reward delivery (Fig. 9) and was selectively elevated when the rats licked in the high-value blocks of the task without regard to reinforcement. These neuronal signals were associated with differences in the duration of licking bouts, with bouts being $\sim 3.4$ times longer in the high-value blocks compared with the low-value blocks (see Results). The duration of licking bouts is classically interpreted as a measure of the palatability, or subjective value, of rewarding solutions (Davis and Smith, 1992). However, in our task design, the intervening periods of nonreinforced licking did not deliver liquid sucrose to the rats. Therefore, we suggest that the elevated MFC theta associated with more persistent licking in the higher-value blocks might have reflected the animal's expectation of the higher-value reward. This interpretation should be verified in future studies (e.g., using shifts in sucrose concentration and fluid volume), which have opposing effects on the duration of licking bouts (Spector et al., 1998; Kaplan et al., 2001).

Whereas the behavioral mechanisms mediating lick-entrained MFC theta will require new experiments to be resolved, our study was able to determine that the signals depend on MFC neurons. Reversible inactivation of the MFC (using muscimol) found evidence for MFC neurons being necessary for the generation of the lick-entrained signals (Fig. 10). Perturbations of the MFC, made by infusing muscimol into the MFC in opposite hemisphere, dramatically attenuated lick-entrained MFC theta in the opposite hemisphere, directly implicating MFC neurons in the generation of the signals.
Together, our findings provide evidence for the MFC processing reward information in an action-centric manner ("the value of licking now") using signals that are synchronized to the lick cycle. Previous studies of MFC reward signaling have inferred value coding upon temporally sustained activity during the period of reward consumption (e.g., Luk and Wallis, 2009). Our findings suggest that neuronal activity in the rostral MFC is temporally sustained during the consumption of rewarding fluids because the animal is licking, and not because of the abstract properties of rewarding fluids.

\section{Frequency-specific entrainment to licking}

Two major rhythms were prevalent in our neuronal recordings. Power was elevated between 2 and $4 \mathrm{~Hz}$ (delta) throughout the performance of the task, but this frequency was not phase-locked to the lick cycle (Fig. 5). A second major rhythm, which was phase-locked to the lick cycle, occurred between 6 and $12 \mathrm{~Hz}$ (theta) (Fig. 5). The phase of this $6-12 \mathrm{~Hz}$ theta rhythm was consistent from lick to lick (intertrial coherence), and the strength of "phase-locking" was enhanced when rats consumed the higher-value reward (Fig. 7). Spike activity was coherent to this theta frequency range for all multiunit recordings that were made simultaneously with the field potential recordings (Fig. 8). Theta-range rhythms are a prominent feature of the frontal cortex across species (Cavanagh and Frank, 2014). In rodents, frontal theta signals represent information about behavioral outcomes and performance adjustment (Narayanan et al., 2013; Laubach et al., 2015), interval timing (Parker et al., 2014; Emmons et al., 2016), freezing during fear conditioning (Karalis et al., 2016), and consummatory action (Horst and Laubach, 2013). The results reported here suggest that frontal theta also has a role in reward processing.

\section{Orolingual aspects of MFC function}

The prominence of theta in rodent frontal cortex during consummatory behavior is interesting as rats naturally lick at frequencies between 6 and $8 \mathrm{~Hz}$ (Weijnen, 1998) and open/close their jaw in the 5-7 Hz range (Sasamoto et al., 1990). These behaviors are controlled by brainstem central pattern generators (Travers et al., 1997). Other orofacial behaviors, such as chewing/mastication (Nakamura and Katakura, 1995), breathing, sniffing, and whisking (Moore et al., 2013), also occur in a rhythmic manner and are controlled by central pattern generators in the brainstem (Moore et al., 2014). These subcortical sensorimotor areas receive projections from the rostral MFC (Yoshida et al., 2009; Haque et al., 2010; Iida et al., 2010), and stimulation of rostral MFC has direct effects on orofacial movement (Brecht et al., 2004; Adachi et al., 2008) and breathing (Hassan et al., 2013). In light of these studies, we propose that one potential function of the rostral MFC might be that it serves as "cingulate motor area" (Shima and Tanji, 1998) controlling orolingual actions and the synchronization between MFC activity and the lick cycle might allow MFC to monitor the consequences of consumption in a temporally precise manner.

\section{Lick-entrained theta is generated by MFC neurons}

Unilateral reversible inactivations decreased theta phase tuning (Fig. 10C,E) in the opposite hemisphere and established that these signals depend on neurons within the MFC. Our inactivations were done unilaterally, and there were no overt behavioral changes to the animals' licking behavior during the inactivation sessions. This is in strong contrast to bilateral inactivations of the same cortical area, which temporally fragments licking and elim- 
inates the expression of learned incentive contrast effects in the task (Parent et al., 2015a, their Figs 3, 7). It is not uncommon for unilateral cross-hemispheric inactivations to show less dramatic effects on behavior (Ambroggi et al., 2008), and it was necessary for our interpretations to have the rats maintain their behavior without normal MFC function. Our findings from the inactivation study bolster evidence for a role of MFC in generating theta signals that are synchronized to the lick cycle, in addition to more distal sources, such as the olfactory system (Fontanini and Bower, 2006) and hippocampus (Paz et al., 2008).

In conclusion, we have shown a role for theta rhythmic activity generated in the rostral part of the rat MFC in tracking the act of consumption of liquid sucrose rewards. If these signals encode relative reward value or enable comparisons among different rewards, then they could enable control over food-based decisions and self-control over eating. New experiments are needed to investigate these issues. In any case, our findings have clinical implications for diseases associated with MFC dysfunction: for example, understanding anhedonia in psychiatric diseases, such as depression and schizophrenia (Gorwood, 2008) and the loss of control over food intake in obesity (Volkow et al., 2011) and eating disorders such as anorexia (Uher et al., 2004). Our findings also raise an alternative interpretation for studies that have reported reward magnitude coding in the MFC without measuring or accounting for the effects of consummatory behavior on neuronal activity.

\section{References}

Adachi K, Murray GM, Lee JC, Sessle BJ (2008) Noxious lingual stimulation influences the excitability of the face primary motor cerebral cortex (face MI) in the rat. J Neurophysiol 100:1234-1244. CrossRef Medline

Agostinelli C, Lund U (2013) R package 'circular': circular statistics (version 0.4-7). https://r-forge.r-project.org/projects/circular/.

Ambroggi F, Ishikawa A, Fields HL, Nicola SM (2008) Basolateral amygdala neurons facilitate reward-seeking behavior by exciting nucleus accumbens neurons. Neuron 59:648-661. CrossRef Medline

Amiez C, Joseph JP, Procyk E (2006) Reward encoding in the monkey anterior cingulate cortex. Cereb Cortex 16:1040-1055. CrossRef Medline

Apicella P, Ljungberg T, Scarnati E, Schultz W (1991) Responses to reward in monkey dorsal and ventral striatum. Exp Brain Res 85:491-500. Medline

Bouret S, Richmond BJ (2010) Ventromedial and orbital prefrontal neurons differentially encode internally and externally driven motivational values in monkeys. J Neurosci 30:8591-8601. CrossRef Medline

Brecht M, Krauss A, Muhammad S, Sinai-Esfahani L, Bellanca S, Margrie TW (2004) Organization of rat vibrissa motor cortex and adjacent areas according to cytoarchitectonics, microstimulation, and intracellular stimulation of identified cells. J Comp Neurol 479:360-373. CrossRef Medline

Cai X, Padoa-Schioppa C (2012) Neuronal encoding of subjective value in dorsal and ventral anterior cingulate cortex. J Neurosci 32:3791-3808. CrossRef Medline

Carelli RM, Deadwyler SA (1994) A comparison of nucleus accumbens neuronal firing patterns during cocaine self-administration and water reinforcement in rats. J Neurosci 14:7735-7746. Medline

Cavanagh JF, Frank MJ (2014) Frontal theta as a mechanism for cognitive control. Trends Cogn Sci 18:414-421. CrossRef Medline

Davis JD, Smith GP (1992) Analysis of the microstructure of the rhythmic tongue movements of rats ingesting maltose and sucrose solutions. Behav Neurosci 106:217-228. CrossRef Medline

de Araujo IE, Gutierrez R, Oliveira-Maia AJ, Pereira A Jr, Nicolelis MA, Simon SA (2006) Neural ensemble coding of satiety states. Neuron 51: 483-494. CrossRef Medline

Delorme A, Makeig S (2004) EEGlab: an open source toolbox for analysis of single-trial EEG dynamics including independent component analysis. J Neurosci Methods 134:9-21. CrossRef Medline

Donnelly NA, Holtzman T, Rich PD, Nevado-Holgado AJ, Fernando AB, Van Dijck G, Holzhammer T, Paul O, Ruther P, Paulsen O, Robbins TW, Dalley JW (2014) Oscillatory activity in the medial prefrontal cortex and nucleus accumbens correlates with impulsivity and reward outcome. PLoS One 9:e111300. CrossRef Medline

Emmons EB, Ruggiero RN, Kelley RM, Parker KL, Narayanan NS (2016) Corticostriatal field potentials are modulated at delta and theta frequencies during interval-timing task in rodents. Front Psychol 7:459. CrossRef Medline

Fontanini A, Bower JM (2006) Slow-waves in the olfactory system: an olfactory perspective on cortical rhythms. Trends Neurosci 29:429-437. CrossRef Medline

Gabbott PL, Warner TA, Jays PR, Bacon SJ (2003) Areal and synaptic interconnectivity of prelimbic (area 32), infralimbic (area 25) and insular cortices in the rat. Brain Res 993:59-71. CrossRef Medline

Gläscher J, Hampton AN, O'Doherty JP (2009) Determining a role for ventromedial prefrontal cortex in encoding action-based value signals during reward-related decision making. Cereb Cortex 19:483-495. CrossRef Medline

Gorwood P (2008) Neurobiological mechanisms of anhedonia. Dialogues Clin Neurosci 10:291-299. Medline

Haque T, Yamamoto S, Masuda Y, Kato T, Sato F, Uchino K, Oka A, Nakamura M, Takeda R, Ono T, Kogo M, Yoshida A (2010) Thalamic afferent and efferent connectivity to cerebral cortical areas with direct projections to identified subgroups of trigeminal premotoneurons in the rat. Brain Res 1346:69-82. CrossRef Medline

Hassan SF, Cornish JL, Goodchild AK (2013) Respiratory, metabolic and cardiac functions are altered by disinhibition of subregions of the medial prefrontal cortex: the prefrontal cortex and autonomic functions. J Physiol 591:6069-6088. CrossRef Medline

Hayden BY, Pearson JM, Platt ML (2009) Fictive reward signals in the anterior cingulate cortex. Science 324:948-950. CrossRef Medline

Hoover WB, Vertes RP (2007) Anatomical analysis of afferent projections to the medial prefrontal cortex in the rat. Brain Struct Funct 212:149-179. CrossRef Medline

Horst NK, Laubach M (2009) The role of rat dorsomedial prefrontal cortex in spatial working memory. Neuroscience 164:444-456. CrossRef Medline

Horst NK, Laubach M (2012) Working with memory: evidence for a role for the medial prefrontal cortex in performance monitoring during spatial delayed alternation. J Neurophysiol 108:3276-3288. CrossRef Medline

Horst NK, Laubach M (2013) Reward-related activity in the medial prefrontal cortex is driven by consumption. Front Neurosci 7:56. CrossRef Medline

Hu H, Vervaeke K, Storm JF (2002) Two forms of electrical resonance at theta frequencies, generated by $\mathrm{M}$-current, $\mathrm{h}$-current and persistent $\mathrm{Na}^{+}$ current in rat hippocampal pyramidal cells. J Physiol 545:783-805. CrossRef Medline

Iida C, Oka A, Moritani M, Kato T, Haque T, Sato F, Nakamura M, Uchino K, Seki S, Bae YC, Takada K, Yoshida A (2010) Corticofugal direct projections to primary afferent neurons in the trigeminal mesencephalic nucleus of rats. Neuroscience 169:1739-1757. CrossRef Medline

Jezzini A, Mazzucato L, La Camera G, Fontanini A (2013) Processing of hedonic and chemosensory features of taste in medial prefrontal and insular networks. J Neurosci 33:18966-18978. CrossRef Medline

Kaplan JM, Baird JP, Grill HJ (2001) Dissociation of licking and volume intake controls in rats ingesting glucose and maltodextrin. Behav Neurosci 115:188-195. CrossRef Medline

Karalis N, Dejean C, Chaudun F, Khoder S, Rozeske RR, Wurtz H, Bagur S, Benchenane K, Sirota A, Courtin J, Herry C (2016) 4-Hz oscillations synchronize prefrontal-amygdala circuits during fear behavior. Nat Neurosci 19:605-612. CrossRef Medline

Laubach M, Caetano MS, Narayanan NS (2015) Mistakes were made: neural mechanisms for the adaptive control of action initiation by the medial prefrontal cortex. J Physiol Paris 109:104-117. CrossRef Medline

Levy DJ, Glimcher PW (2011) Comparing apples and oranges: using reward-specific and reward-general subjective value representation in the brain. J Neurosci 31:14693-14707. CrossRef Medline

Luk CH, Wallis JD (2009) Dynamic encoding of responses and outcomes by neurons in medial prefrontal cortex. J Neurosci 29:7526-7539. CrossRef Medline

Moore JD, Deschênes M, Furuta T, Huber D, Smear MC, Demers M, Kleinfeld D (2013) Hierarchy of orofacial rhythms revealed through whisking and breathing. Nature 497:205-210. CrossRef Medline

Moore JD, Kleinfeld D, Wang F (2014) How the brainstem controls orofa- 
cial behaviors comprised of rhythmic actions. Trends Neurosci 37:370380. CrossRef Medline

Nakamura Y, Katakura N (1995) Generation of masticatory rhythm in the brainstem. Neurosci Res 23:1-19. CrossRef Medline

Narayanan NS, Laubach M (2006) Top-down control of motor cortex ensembles by dorsomedial prefrontal cortex. Neuron 52:921-931. CrossRef Medline

Narayanan NS, Cavanagh JF, Frank MJ, Laubach M (2013) Common medial frontal mechanisms of adaptive control in humans and rodents. Nat Neurosci 16:1888-1895. CrossRef Medline

Narayanan NS, Horst NK, Laubach M (2006) Reversible inactivations of rat medial prefrontal cortex impair the ability to wait for a stimulus. Neuroscience 139:865-876. CrossRef Medline

Padoa-Schioppa C, Assad JA (2006) Neurons in the orbitofrontal cortex encode economic value. Nature 441:223-226. CrossRef Medline

Parent MA, Amarante LM, Liu B, Weikum D, Laubach M (2015a) The medial prefrontal cortex is crucial for the maintenance of persistent licking and the expression of incentive contrast. Front Integr Neurosci 9:23. CrossRef Medline

Parent MA, Amarante LM, Swanson K, Laubach M (2015b) Cholinergic and ghrelinergic receptors and KCNQ channels in the medial PFC regulate the expression of palatability. Front Behav Neurosci 9:284. CrossRef Medline

Parker KL, Chen KH, Kingyon JR, Cavanagh JF, Narayanan NS (2014) D1dependent $4 \mathrm{~Hz}$ oscillations and ramping activity in rodent medial frontal cortex during interval timing. J Neurosci 34:16774-16783. CrossRef Medline

Paxinos G, Watson C (1997) The rat brain in stereotaxic coordinates, Ed 3. San Diego: Elsevier Academic.

Paz R, Bauer EP, Paré D (2008) Theta synchronizes the activity of medial prefrontal neurons during learning. Learn Mem 15:524-531. CrossRef Medline

Petykó Z, Tóth A, Szabó I, Gálosi R, Lénárd L (2009) Neuronal activity in rat medial prefrontal cortex during sucrose solution intake. Neuroreport 20: 1235-1239. CrossRef Medline

Petykó Z, Gálosi R, Tóth A, Máté K, Szabó I, Szabó I, Karádi Z, Lénárd L (2015) Responses of rat medial prefrontal cortical neurons to Pavlovian conditioned stimuli and to delivery of appetitive reward. Behav Brain Res 287:109-119. CrossRef Medline

Roesch MR, Olson CR (2004) Neuronal activity related to reward value and motivation in primate frontal cortex. Science 304:307-310. CrossRef Medline

Sasamoto K, Zhang G, Iwasaki M (1990) Two types of rhythmical jaw movements evoked by stimulation of the rat cortex. Shika Kiso Igakkai Zasshi 32:57-68. Medline

Shidara M, Richmond BJ (2002) Anterior cingulate: single neuronal signals related to degree of reward expectancy. Science 296:1709-1711. CrossRef Medline

Shima K, Tanji J (1998) Role for cingulate motor area cells in voluntary movement selection based on reward. Science 282:1335-1338. CrossRef Medline

Spector AC, Klumpp PA, Kaplan JM (1998) Analytical issues in the evaluation of food deprivation and sucrose concentration effects on the microstructure of licking behavior in the rat. Behav Neurosci 112:678-694. CrossRef Medline

Travers JB, Dinardo LA, Karimnamazi H (1997) Motor and premotor mechanisms of licking. Neurosci Biobehav Rev 21:631-647. CrossRef Medline

Uher R, Murphy T, Brammer MJ, Dalgleish T, Phillips ML, Ng VW, Andrew CM, Williams SC, Campbell IC, Treasure J (2004) Medial prefrontal cortex activity associated with symptom provocation in eating disorders. Am J Psychiatry 161:1238-1246. CrossRef Medline

van Duuren E, Escámez FA, Joosten RN, Visser R, Mulder AB, Pennartz CM (2007) Neural coding of reward magnitude in the orbitofrontal cortex of the rat during a five-odor olfactory discrimination task. Learn Mem 14: 446-456. CrossRef Medline

Volkow ND, Wang GJ, Baler RD (2011) Reward, dopamine and the control of food intake: implications for obesity. Trends Cogn Sci 15:37-46. CrossRef Medline

Watanabe M (1996) Reward expectancy in primate prefrontal neurons. Nature 382:629-632. CrossRef Medline

Weijnen JA (1998) Licking behavior in the rat: measurement and situational control of licking frequency. Neurosci Biobehav Rev 22:751-760. CrossRef Medline

Widmann A, Schröger E (2012) Filter effects and filter artifacts in the analysis of electrophysiological data. Front Psychol 3:233. CrossRef Medline

Yoshida A, Taki I, Chang Z, Iida C, Haque T, Tomita A, Seki S, Yamamoto S, Masuda Y, Moritani M, Shigenaga Y (2009) Corticofugal projections to trigeminal motoneurons innervating antagonistic jaw muscles in rats as demonstrated by anterograde and retrograde tract tracing. J Comp Neurol 514:368-386. CrossRef Medline 